\title{
U-duct turbulent-flow computation with the ST-VMS method and isogeometric discretization
}

\author{
Levent Aydinbakar $^{1} \cdot$ Kenji Takizawa $^{1} \cdot$ Tayfun E. Tezduyar $^{2,3} \cdot$ Daisaku Matsuda $^{1}$
}

Received: 8 October 2020 / Accepted: 11 December 2020 / Published online: 13 February 2021

(c) The Author(s) 2021

\begin{abstract}
The U-duct turbulent flow is a known benchmark problem with the computational challenges of high Reynolds number, high curvature and strong flow dependence on the inflow profile. We use this benchmark problem to test and evaluate the Space-Time Variational Multiscale (ST-VMS) method with ST isogeometric discretization. A fully-developed flow field in a straight duct with periodicity condition is used as the inflow profile. The ST-VMS serves as the core method. The ST framework provides higher-order accuracy in general, and the VMS feature of the ST-VMS addresses the computational challenges associated with the multiscale nature of the unsteady flow. The ST isogeometric discretization enables more accurate representation of the duct geometry and increased accuracy in the flow solution. In the straight-duct computations to obtain the inflow velocity, the periodicity condition is enforced with the ST Slip Interface method. All computations are carried out with quadratic NURBS meshes, which represent the circular arc of the duct exactly in the U-duct computations. We investigate how the results vary with the time-averaging range used in reporting the results, mesh refinement, and the Courant number. The results are compared to experimental data, showing that the ST-VMS with ST isogeometric discretization provides good accuracy in this class of flow problems.
\end{abstract}

Keywords Space-Time Variational Multiscale method - ST-VMS · Isogeometric discretization · NURBS mesh · Turbulent flow $\cdot$ U-duct

\section{Introduction}

In the benchmarking context of the U-duct turbulent flow, which has a number of computational challenges, we conduct test and evaluation of the Space-Time Variational Multiscale (ST-VMS) method [1-3] with ST isogeometric discretization [1,4-6]. Turbulent-flow test and evaluation studies were conducted earlier for the ST-VMS (see [5,7,8]), but the computations in $[7,8]$ were with finite element discretization, and the computation in [5] was with a significantly milder

Kenji Takizawa

Kenji.Takizawa@tafsm.org

Tayfun E. Tezduyar

tezduyar@tafsm.org

1 Department of Modern Mechanical Engineering, Waseda University, 3-4-1 Ookubo, Shinjuku-ku, Tokyo 169-8555, Japan

2 Mechanical Engineering, Rice University - MS 321, 6100 Main Street, Houston, TX 77005, USA

3 Faculty of Science and Engineering, Waseda University, 3-4-1 Ookubo, Shinjuku-ku, Tokyo 169-8555, Japan test problem, a straight pipe with circular cross-section. Furthermore, here we use the latest stabilization parameters [9] designed in conjunction with the ST-VMS, with the latest element length expressions [10].

\subsection{Stabilized and VMS ST computational methods}

The stabilized and VMS ST computational methods started with the Deforming-Spatial-Domain/Stabilized ST(DSD/SST) method [11-13]. The DSD/SST was introduced for computation of flows with moving boundaries and interfaces (MBI), including fluid-structure interaction (FSI). In flow computations with MBI, the DSD/SST functions as a moving-mesh method. Moving the fluid mechanics mesh to follow an interface enables mesh-resolution control near the interface and, consequently, high-resolution boundary-layer representation near fluid-solid interfaces.

Stabilized and VMS methods have for decades been playing a core-method role in flow analysis with semidiscrete and ST computational methods. The incompressibleflow Streamline-Upwind/Petrov-Galerkin (SUPG) [14,15] 
and compressible-flow SUPG [16-18] methods are two of the earliest and most widely used stabilized methods. The incompressible-flow Pressure-Stabilizing/PetrovGalerkin (PSPG) method [11,19], with its Stokes-flow version introduced in [20], is also among the earliest and most widely used. These methods bring numerical stability in computation of flow problems at high Reynolds or Mach numbers and when using equal-order basis functions for velocity and pressure in incompressible flows. Because the methods are residual-based, the stabilization is achieved without loss of accuracy. The residual-based VMS (RBVMS) [2124], which is also widely used now, subsumes its precursor SUPG/PSPG.

Because the stabilization components of the original DSD/SST are the SUPG and PSPG stabilizations, it is now also called "ST-SUPS." The ST-VMS [1-3] is the VMS version of the DSD/SST. The VMS components of the ST-VMS are from the RBVMS. The ST-VMS, which subsumes its precursor ST-SUPS, has two more stabilization terms beyond those in the ST-SUPS, and the additional terms give the method better turbulence modeling features. The ST-SUPS and ST-VMS, because of the higher-order accuracy of the ST framework (see $[1,2]$ ), are desirable also in computations without MBI.

As a moving-mesh method, the DSD/SST is an alternative to the Arbitrary Lagrangian-Eulerian (ALE) method, which is older (see, for example, [25]) and more commonly used. The ALE-VMS method [26-32] is the VMS version of the ALE. It succeeded the ST-SUPS and ALESUPS [33] and preceded the ST-VMS. The ALE-SUPS, RBVMS and ALE-VMS have been applied to many classes of FSI, MBI and fluid mechanics problems. The classes of problems include ram-air parachute FSI [33], wind turbine aerodynamics and FSI [34-46], more specifically, verticalaxis wind turbines (VAWTs) [43,44,47,48], floating wind turbines [49], wind turbines in atmospheric boundary layers [42-44,50-52], and fatigue damage in wind turbine blades [53], patient-specific cardiovascular fluid mechanics and FSI [26,54-59], biomedical-device FSI [60-67], ship hydrodynamics with free-surface flow and fluid-object interaction [68,69], hydrodynamics and FSI of a hydraulic arresting gear $[70,71]$, hydrodynamics of tidal-stream turbines with free-surface flow [72], passive-morphing FSI in turbomachinery [73], bioinspired FSI for marine propulsion [74, 75], bridge aerodynamics and fluid-object interaction [7678], and mixed ALE-VMS/Immersogeometric computations $[63-65,79,80]$ in the framework of the Fluid-Solid Interface-Tracking/Interface-Capturing Technique [81]. Recent advances in stabilized and multiscale methods may be found for stratified incompressible flows in [82], for divergence-conforming discretizations of incompressible flows in [83], and for compressible flows with emphasis on gas-turbine modeling in $[84,85]$.
In flow computations with FSI or MBI, the ST-SUPS and ST-VMS require a mesh moving method. Mesh update has two components: moving the mesh for as long as it is possible, which is the core component, and full or partial remeshing when the element distortion becomes too high. The key objectives of a mesh moving method should be to maintain the element quality near solid surfaces and to minimize remeshing frequency. A number of well-performing mesh moving methods were developed in conjunction with the ST-SUPS and ST-VMS. The first one, introduced in [8689], was the Jacobian-based stiffening (JBS), which is now called, for reasons explained in [90,91], "mesh-Jacobianbased stiffening." The most recent ones are the element-based mesh relaxation [92], where the mesh motion is determined by using the large-deformation mechanics equations and an element-based zero-stress-state (ZSS), a mesh moving method [91] based on fiber-reinforced hyperelasticity and optimized ZSS, and a linear-elasticity-based mesh moving method with no cycle-to-cycle accumulated distortion [93].

The ST-SUPS and ST-VMS have also been applied to many classes of FSI, MBI and fluid mechanics problems (see [94] for a comprehensive summary of the work prior to July 2018). The classes of problems include spacecraft parachute analysis for the landing-stage parachutes [29,92, 95-97], cover-separation parachutes [98] and the drogue parachutes [99-101], wind turbine aerodynamics for horizontal-axis wind turbine (HAWT) rotors [7,29,34,102], full HAWTs [40,103-105] and VAWTs [43-46,106,107], flapping-wing aerodynamics for an actual locust [4,29, 108,109], bioinspired MAVs [104,105,110,111] and wingclapping [112,113], blood flow analysis of cerebral aneurysms [104,114], stent-blocked aneurysms [114-116], aortas $[66,67,90,117-120]$, heart valves $[66,67,90,105,112$, $119,121-125]$ and coronary arteries in motion [126], spacecraft aerodynamics $[8,98]$, thermo-fluid analysis of ground vehicles and their tires $[3,51,52,122]$, thermo-fluid analysis of disk brakes [127], flow-driven string dynamics in turbomachinery $[45,46,128-130]$, flow analysis of turbocharger turbines [5,131-134], flow around tires with road contact and deformation [9,122,135-137], fluid films [137,138], ramair parachutes $[6,51,52]$, and compressible-flow spacecraft parachute aerodynamics $[139,140]$.

\subsection{ST Slip Interface method}

The ST Slip Interface (ST-SI) method was introduced in [106], in the context of incompressible-flow equations, to retain the desirable moving-mesh features of the ST-VMS and ST-SUPS in computations involving spinning solid surfaces, such as a turbine rotor. The mesh covering the spinning surface spins with it, retaining the high-resolution representation of the boundary layers, while the mesh on the other side of the SI remains unaffected. This is accomplished by 
adding to the ST-VMS formulation interface terms similar to those in the version of the ALE-VMS for computations with sliding interfaces [141,142]. The interface terms account for the compatibility conditions for the velocity and stress at the SI, accurately connecting the two sides of the solution. An ST-SI version where the SI is between fluid and solid domains was also presented in [106]. The SI in that case is a "fluid-solid SI" rather than a standard "fluid-fluid SI" and enables weak enforcement of the Dirichlet boundary conditions for the fluid. The ST-SI introduced in [127] for the coupled incompressible-flow and thermal-transport equations retains the high-resolution representation of the thermo-fluid boundary layers near spinning solid surfaces. These ST-SI methods have been applied to aerodynamic analysis of VAWTs [43-46,106,107], thermo-fluid analysis of disk brakes [127], flow-driven string dynamics in turbomachinery [45,46,128-130], flow analysis of turbocharger turbines [5,131-134], flow around tires with road contact and deformation [9,122,135-137], fluid films [137,138], aerodynamic analysis of ram-air parachutes [6,51,52], and flow analysis of heart valves [66,67,119,123-125] and ventriclevalve-aorta sequences [90]. In the ST-SI version presented in [106] the SI is between a thin porous structure and the fluid on its two sides. This enables dealing with the porosity in a fashion consistent with how the standard fluid-fluid SIs are dealt with and how the Dirichlet conditions are enforced weakly with fluid-solid SIs. This version also enables handling thin structures that have T-junctions. This method has been applied to incompressible-flow aerodynamic analysis of ram-air parachutes with fabric porosity $[6,51,52]$.

\subsection{ST Isogeometric Analysis}

The success with Isogeometric Analysis (IGA) basis functions in space $[26,54,141,143]$ motivated the integration of the ST methods with isogeometric discretization, which is broadly called "ST-IGA." The ST-IGA was introduced in [1]. Computations with the ST-VMS and ST-IGA were first reported in [1] in a 2D context, with IGA basis functions in space for flow past an airfoil, and in both space and time for the advection equation. Using higher-order basis functions in time enables deriving full benefit from using higher-order basis functions in space. This was demonstrated with the stability and accuracy analysis given in [1] for the advection equation.

The ST-IGA with IGA basis functions in time enables a more accurate representation of the motion of the solid surfaces and a mesh motion consistent with that. This was pointed out in [1,2] and demonstrated in [4,108,110]. It also enables more efficient temporal representation of the motion and deformation of the volume meshes, and more efficient remeshing. These motivated the development of the ST/NURBS Mesh Update Method (STNMUM) [4,108,110], with the name coined in [103]. The STNMUM has a wide scope that includes spinning solid surfaces. With the spinning motion represented by quadratic NURBS in time, and with sufficient number of temporal patches for a full rotation, the circular paths are represented exactly. A "secondary mapping" $[1,2,4,29]$ enables also specifying a constant angular velocity for invariant speeds along the circular paths. The ST framework and NURBS in time also enable, with the "ST-C" method, extracting a continuous representation from the computed data and, in large-scale computations, efficient data compression [3,122,127-130,144]. The STNMUM and the ST-IGA with IGA basis functions in time have been used in many $3 \mathrm{D}$ computations. The classes of problems solved are flapping-wing aerodynamics for an actual locust [4,29,108,109], bioinspired MAVs [104, $105,110,111]$ and wing-clapping [112,113], separation aerodynamics of spacecraft [98], aerodynamics of horizontalaxis [40,103-105] and vertical-axis [43-46,106,107] wind turbines, thermo-fluid analysis of ground vehicles and their tires [3,51,122], thermo-fluid analysis of disk brakes [127], flow-driven string dynamics in turbomachinery $[45,46,128$ 130], flow analysis of turbocharger turbines [5,131-134], and flow analysis of coronary arteries in motion [126].

The ST-IGA with IGA basis functions in space enables more accurate representation of the geometry and increased accuracy in the flow solution. It accomplishes that with fewer control points, and consequently with larger effective element sizes. That in turn enables using larger time-step sizes while keeping the Courant number at a desirable level for good accuracy. It has been used in ST computational flow analysis of turbocharger turbines [5,131-134], flowdriven string dynamics in turbomachinery [45,46,129,130], ram-air parachutes [6,51,52], spacecraft parachutes [140], aortas [66,67,119,120], heart valves [66,67,119,123-125], ventricle-valve-aorta sequences [90], coronary arteries in motion [126], tires with road contact and deformation [9, 136,137], fluid films [137,138], and VAWTs [45,46,107]. The image-based arterial geometries used in patient-specific arterial FSI computations do not come from the ZSS of the artery. A number of methods [27,29,145-154] have been proposed for estimating the ZSS required in the computations. Using IGA basis functions in space is now a key part of some of the newest ZSS estimation methods [66,152-155] and related shell analysis [156]. The IGA has also been successfully applied to the structural analysis of wind turbine blades [157-161].

\subsection{Stabilization parameters and element lengths}

In all the semi-discrete and ST stabilized and VMS methods discussed in Sect. 1.1, an embedded stabilization parameter, known as " $\tau$," plays a significant role (see [29]). This parameter involves a measure of the local length scale (also 
known as "element length") and other parameters such as the element Reynolds and Courant numbers. The interface terms in the ST-SI also involve element length, in the direction normal to the interface. Various element lengths and $\tau \mathrm{s}$ were proposed, starting with those in $[14,15]$ and $[16-$ $18]$, followed by the ones introduced in $[162,163]$. In many cases, the element length was seen as an advection length scale, in the flow-velocity direction. The $\tau$ definition introduced in [163], which is for the advective limit and is now called " $\tau_{\text {SUGN1" }}$ " and the corresponding element length is now called " $h_{\text {UGN"), automatically yields lower values for }}$ higher-order finite element basis functions (see [164,165]).

Calculating the $\tau$ s based on the element-level matrices and vectors was introduced in [166] in the context of the advection-diffusion equation and the Navier-Stokes equations of incompressible flows. These definitions are expressed in terms of the ratios of the norms of the matrices or vectors. They automatically take into account the local length scales, advection field and the element Reynolds number. The definitions based on the element-level vectors were shown $[166,167]$ to address the difficulties reported at small time-step sizes. A second element length scale, in the solution-gradient direction and called " $h_{\mathrm{RGN}}$," was introduced in $[168,169]$. Recognizing this as a diffusion length scale, a new stabilization parameter for the diffusive limit, " $\tau_{\text {SUGN3 } 3}$," was introduced in $[169,170]$, to be used together with $\tau_{\mathrm{SUGN} 1}$ and " $\tau_{\mathrm{SUGN} 2}$," the parameters for the advective and transient limits. For the stabilized ST methods,

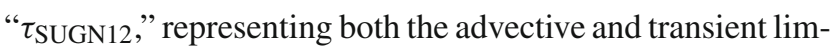
its, was also introduced in $[168,169]$.

Some new options for the stabilization parameters used with the SUPS and VMS were proposed in $[3,4,7,103,171]$. These include a fourth $\tau$ component, " $\tau_{\text {SUGN } 4}$ " [3], which was introduced for the VMS, considering one of the two extra stabilization terms the VMS has compared to the SUPS. They also include stabilization parameters [3] for the thermal-transport part of the VMS for the coupled incompressible-flow and thermal-transport equations.

Some of the stabilization parameters described in this subsection were also used in computations with other SUPG-like methods, such as the computations reported in [73,172-184].

The stabilization parameters and element lengths discussed in this subsection so far were all originally intended for finite element discretization but quite often used also for isogeometric discretization. The element lengths and stabilization parameters introduced in [185] target isogeometric discretization but are also applicable to finite element discretization. They were introduced in the context of the advection-diffusion equation and the Navier-Stokes equations of incompressible flows. The direction-dependent element length expression was outcome of a conceptually simple derivation. The key components of the derivation are mapping the direction vector from the physical ST element to the parent ST element, accounting for the discretization spacing along each of the parametric coordinates, and mapping what has been obtained in the parent element back to the physical element. The test computations presented in [185] for pure-advection cases, including those with discontinuous solution, showed that the element lengths and stabilization parameters proposed result in good solution profiles. The test computations also showed that the "UGN" parameters give reasonably good solutions even with NURBS basis functions. The stabilization parameters given in [9], which were mostly from [185], were the latest ones designed in conjunction with the ST-VMS.

In general, we decide what parametric space to use based on reasons like numerical integration efficiency or implementation convenience. Obviously, choices based on such reasons should not influence the method in substance. We require the element lengths, including the direction-dependent element lengths, to have node-numbering invariance for all element types, including simplex elements. The direction-dependent element length expression introduced in [186] meets that requirement. This is accomplished by using in the element length calculations for simplex elements a preferred parametric space instead of the standard integration parametric space. The element length expressions based on the two parametric spaces were evaluated in [186] in the context of simplex elements. It was shown that when the element length expression is based on the integration parametric space, the variation with the node numbering could be by a factor as high as 1.9 for 3D elements and 2.2 for ST elements. It was also shown that the element length expression based on the integration parametric space could overestimate the element length by a factor as high as 2.8 for 3D elements and 3.2 for ST elements.

Targeting B-spline meshes for complex geometries, new direction-dependent element length expressions were introduced in [10]. These latest element length expressions are outcome of a clear and convincing derivation and more suitable for element-level evaluation. The new expressions are based on a preferred parametric space, instead of the standard integration parametric space, and a transformation tensor that represents the relationship between the integration and preferred parametric spaces. We do not want the element splitting to influence the actual discretization, which is represented by the control or nodal points. Therefore, the local length scale should be invariant with respect to element splitting. That invariance is a crucial requirement in element definition, because unlike the element definition choices based on implementation convenience or computational efficiency, it influences the solution. It was proven in [187] that the local-length-scale expressions introduced in [10] meet that requirement.

The direction-dependent local-length-scale expressions introduced in $[10,185]$ have been used in computational flow analysis of turbocharger turbines [133,134], compressible- 
flow spacecraft parachutes [140], tires with road contact and deformation [9,137], fluid films [137,138], heart valves [125], ventricle-valve-aorta sequences [90], and tsunami-shelter VAWTs [107]. They have also been used in [85], in the context of gas turbine computational flow analysis with isogeometric discretization, in calculating the Courant number based on the NURBS mesh local length scale in the flow direction.

\subsection{U-duct turbulent flow}

The U-duct turbulent flow is a known benchmark problem with sufficient experimental data (see, for example, [188]). The computational challenges encountered include high Reynolds numbers, high curvature and strong flow dependence on the inflow profile. In the U-duct computations we present, a fully-developed flow field in a straight duct with periodicity condition is used as the inflow profile. In the straight-duct computations to obtain the inflow velocity, the periodicity condition is enforced with the ST-SI method. Both the straight-duct and U-duct computations are carried out with quadratic NURBS meshes, which represent the circular arc of the duct exactly in the U-duct computations. We investigate how the results vary with the time-averaging range used in reporting the results, mesh refinement, and the Courant number. The results are compared to experimental data [188] to show how the ST-VMS with ST isogeometric discretization performs in this class of flow problems.

\subsection{Outline of the remaining sections}

In Sect. 2, we provide the definitions used in the data analysis. The straight-duct computations are presented in Sect. 3, and the U-duct computations in Sect. 4. The concluding remarks are given in Sect. 5. The ST-VMS and ST-SI methods and the stabilization parameters are given in Appendices A and B.

\section{Definitions for the data analysis}

\subsection{Scale separation}

We split the velocity scales as

$\mathbf{u}=\overline{\mathbf{u}}+\mathbf{u}^{\prime}$,

where the overbar indicates the time-averaging over the range $\mathcal{T}=\left(T_{1}, T_{2}\right)$

$\bar{f}=\frac{1}{T_{2}-T_{1}} \int_{T_{1}}^{T_{2}} f \mathrm{~d} t$ and $f$ can be a vector or scalar. We note that this scale separation is different from the VMS scale separation. It is used only for post processing. We extend that to the ST context as

$$
\begin{aligned}
\overline{\bar{f}} & =\frac{1}{\int_{\mathcal{T}} \int_{\Omega_{t}} \mathrm{~d} \Omega \mathrm{d} t} \int_{\mathcal{T}} \int_{\Omega_{t}} f \mathrm{~d} \Omega \mathrm{d} t \\
& =\frac{1}{\int_{Q} \mathrm{~d} Q} \int_{Q} f \mathrm{~d} Q,
\end{aligned}
$$

where $Q=\left\{\mathbf{x}(t) \in \Omega_{t} \mid t \in \mathcal{T}\right\}$ is the ST domain.

We define the $L_{q}$ norm of a scalar as

$\|f\|_{q, \mathcal{T}}=\left(\frac{1}{T_{2}-T_{1}} \int_{T_{1}}^{T_{2}}|f|^{q} \mathrm{~d} t\right)^{\frac{1}{q}}$.

We extend that to the ST context as

$$
\begin{aligned}
\|f\|_{q, Q} & =\left(\frac{1}{\int_{\mathcal{T}} \int_{\Omega_{t}} \mathrm{~d} \Omega \mathrm{d} t} \int_{\mathcal{T}} \int_{\Omega_{t}}|f|^{q} \mathrm{~d} \Omega \mathrm{d} t\right)^{\frac{1}{q}} \\
& =\left(\frac{1}{\int_{Q} \mathrm{~d} Q} \int_{Q}|f|^{q} \mathrm{~d} Q\right)^{\frac{1}{q}} .
\end{aligned}
$$

\subsection{Nondimensionalization}

With $\rho, U$ and $D$ being the scales for the density, velocity and length, we define the scaled quantities as

$$
\begin{aligned}
\mathbf{u}^{*} & =\frac{\mathbf{u}}{U}, \\
t^{*} & =\frac{t U}{D}, \\
p^{*} & =\frac{p}{\rho U^{2}},
\end{aligned}
$$

where $p$ is the pressure. For notation convenience, we drop the asterisk, which results in $\rho=1$, for example.

\subsection{Wall-related scaling}

We define the scaled wall-normal coordinate as

$y^{+}=\frac{y u_{\tau}}{v}$,

where $y$ is the coordinate along the wall normal, $v=\mu / \rho$ is the kinematic viscosity, and $\mu$ is the viscosity. The friction velocity $u_{\tau}$ is defined as

$u_{\tau}=\sqrt{\frac{\left\|\mathbf{h}_{\mathrm{v}}\right\|}{\rho}}$,

where $\mathbf{h}_{\mathrm{v}}$ is the wall shear stress. The streamwise velocity is scaled near the wall as $u^{+}=\frac{u_{\mathrm{s}}}{u_{\tau}}$. We note that whether 


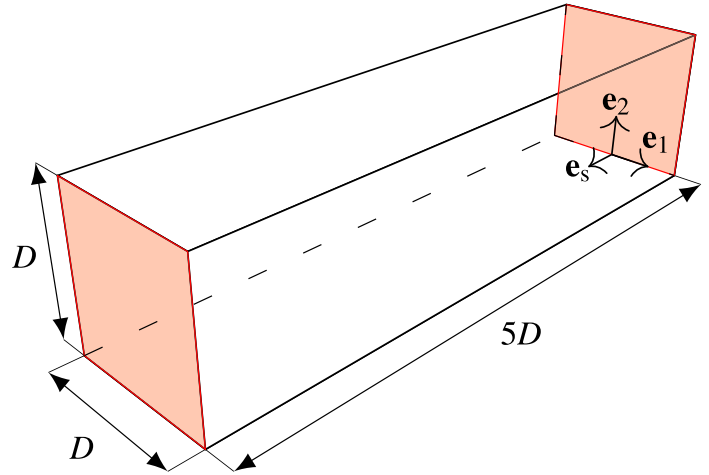

Fig. 1 Straight duct. Computational domain and the coordinate basis vectors. The two end planes are colored red to remind the reader that we are enforcing periodicity condition on those planes. (Color figure online)

the scaling we do here is done after or before the scaling in Sect. 2.2 does not change the outcome.

\section{Straight duct with periodicity condition}

\subsection{Problem setup}

The duct has a $D \times D$ cross-section and is $5 D$ long. Figure 1 shows the computational domain and the coordinate basis vectors $\mathbf{e}_{1}, \mathbf{e}_{2}$ and $\mathbf{e}_{\mathrm{s}}$. In the Reynolds number definition $\mathrm{Re}=$ $\frac{U D}{v}, U$ is streamwise velocity averaged in time and over the cross-section. We compute the cases $\mathrm{Re}=4 \times 10^{4}$ and $10^{5}$. In the data analysis, we express the velocity components as $u_{k}=\mathbf{u} \cdot \mathbf{e}_{k}$, where $k=1,2$, s.

\subsection{Mesh}

Figure 2 shows the mesh used for both $\operatorname{Re}=4 \times 10^{4}$ and $10^{5}$, which is made of $72^{3}$ quadratic NURBS elements. The mesh is uniform in the streamwise direction. The normal-direction thickness for the first layer of elements near the wall results in $y^{+}=0.43$ and 0.95 for $\operatorname{Re}=4 \times 10^{4}$ and $10^{5}$. In calculating the $y^{+}$values based on Eqs. (11) and (12), $\left\|\mathbf{h}_{\mathrm{v}}\right\|$ is estimated from the pipe friction factor $f$ given [189] as

$\frac{1}{f^{0.5}}=2 \log \left(\operatorname{Re} f^{0.5}\right)-0.8$.

The $f$ values corresponding to $\operatorname{Re}=4 \times 10^{4}$ and $10^{5}$ are $2.2 \times 10^{-2}$ and $1.8 \times 10^{-2}$.

\subsection{Boundary conditions}

The no-slip conditions on the walls are enforced weakly (see Appendix A.2.2). In each case of Reynolds number, the pressure difference specified across the SI (see Appendix A.2.1) is
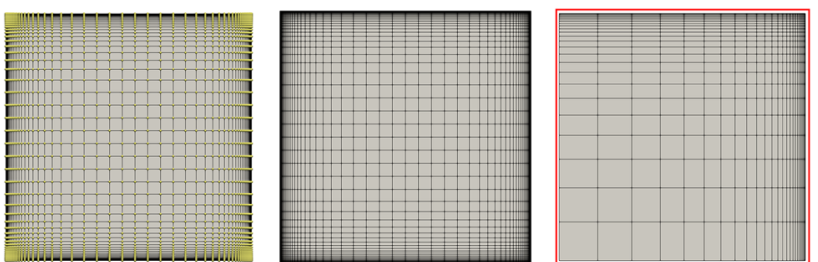

Fig. 2 Straight duct. Control mesh (left). The yellow circles are the control points. The corresponding mesh (middle) and its part in the red frame (right). (Color figure online)

adjusted until we achieve a Reynolds number close enough to the case Reynolds number. That becomes the actual Reynolds number we compute.

\subsection{Computational conditions}

We use the ST-VMS, with the stabilization parameters given by Eqs. (22)-(24), (33) and (34). The time-step size $\Delta t$ is determined from the Courant number $C_{\Delta t}=\frac{U \Delta t}{h_{\mathrm{s}}}$, where $h_{\mathrm{s}}$ is the "apparent" element length ${ }^{1}$ in the streamwise direction. We set $C_{\Delta t}=0.322$. The number of nonlinear iterations per time step is 3, and the number of GMRES iterations per nonlinear iteration is 500. We define $T=L / U$, where $L$ is the duct length. After achieving the actual Reynolds number we compute, the duration we compute for data extraction is $20 T$, which is equivalent to 4474 time steps.

\subsection{Results}

In computations we carry out to adjust the pressure difference specified across the SI, we achieve the Reynolds number values of $3.96 \times 10^{4}$ and $9.98 \times 10^{4}$ at scaled pressure gradient values $5.6 \times 10^{-2}$ and $4.7 \times 10^{-2}$. In both cases, the difference from the case Reynolds number is no more than $1 \%$.

Figure 3 shows, for $\operatorname{Re}=10^{5}, \overline{\bar{u}}_{\mathrm{s}}$ and $\left\|u_{\mathrm{s}}^{\prime}\right\|_{2, Q}$, together with the experimental data from [188]. Figure 4 shows, for both $\operatorname{Re}=4 \times 10^{4}$ and $10^{5}, \overline{\overline{u^{+}}}$, together with the DNS data for $\operatorname{Re}=4 \times 10^{4}$ from [190].

\section{U-duct}

\subsection{Problem setup}

Figure 5 shows the computational domain and the coordinate basis vectors. We compute the case $\operatorname{Re}=10^{5}$. The locations where the flow characteristics are reported are shown in Fig. 6.

\footnotetext{
${ }^{1}$ We note that this is not the element length calculated from the definition introduced in $[10,185]$ for isogeometric discretization and to be used as the local length scale in stabilization parameters.
} 

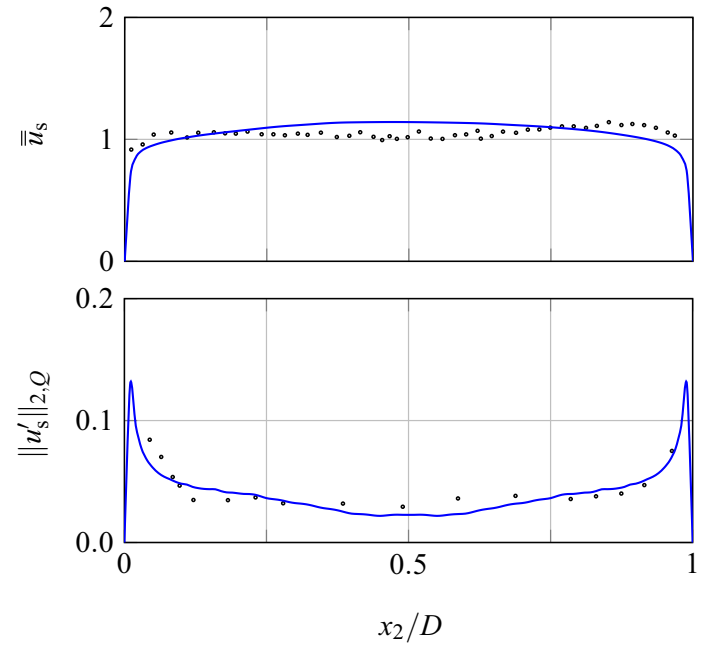

- ST-VMS $\quad \cdots$ Experiment

Fig. 3 Straight duct. $\operatorname{Re}=10^{5}$. $\overline{\bar{u}}_{\mathrm{s}}$ and $\left\|u_{s}^{\prime}\right\|_{2, Q}$ with $Q=$ $\left\{\mathbf{x}=\left(0, x_{2}, x_{\mathrm{s}}\right) \mid x_{\mathrm{s}} \in(0,5 D), t \in(8.5 T, 20 T)\right\}$. The experimental data is from [188]

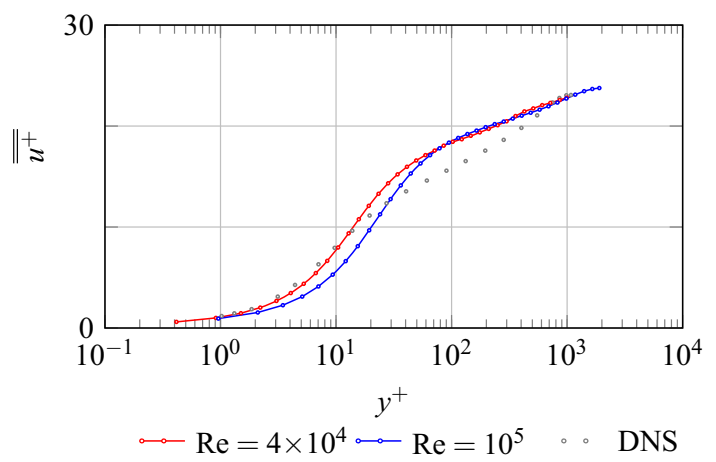

Fig. 4 Straight duct. $\operatorname{Re}=4 \times 10^{4}$ and $\operatorname{Re}=10^{5} . \overline{\overline{u^{+}}}$with $Q=$ $\left\{\mathbf{x}=\left(0, x_{2}, x_{\mathrm{s}}\right) \mid x_{s} \in(0,5 D), t \in(8.5 T, 20 T)\right\}$. The DNS data is for $\mathrm{Re}=4 \times 10^{4}$ and from [190]

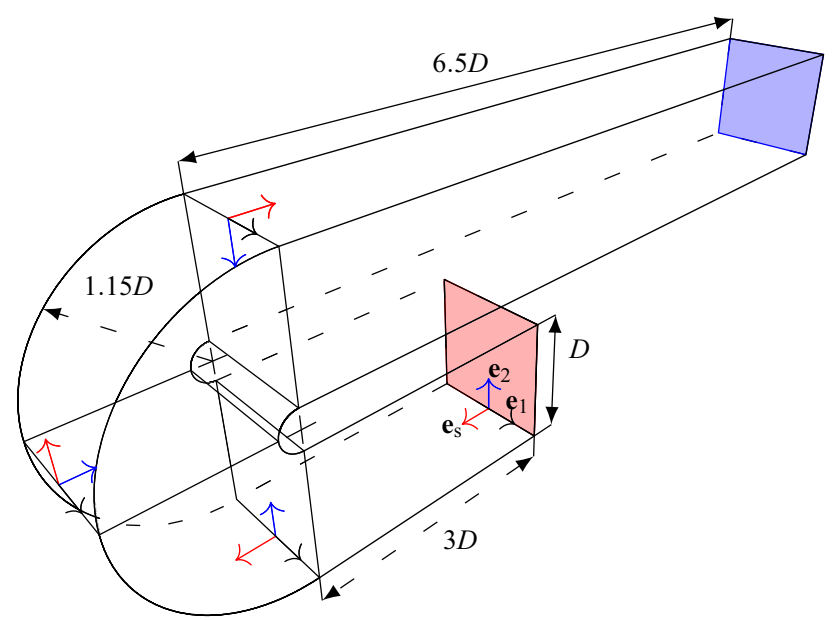

Fig. 5 U-duct. Computational domain and the coordinate basis vectors. The red plane is the inlet, and the blue plane is the outlet. (Color figure online)

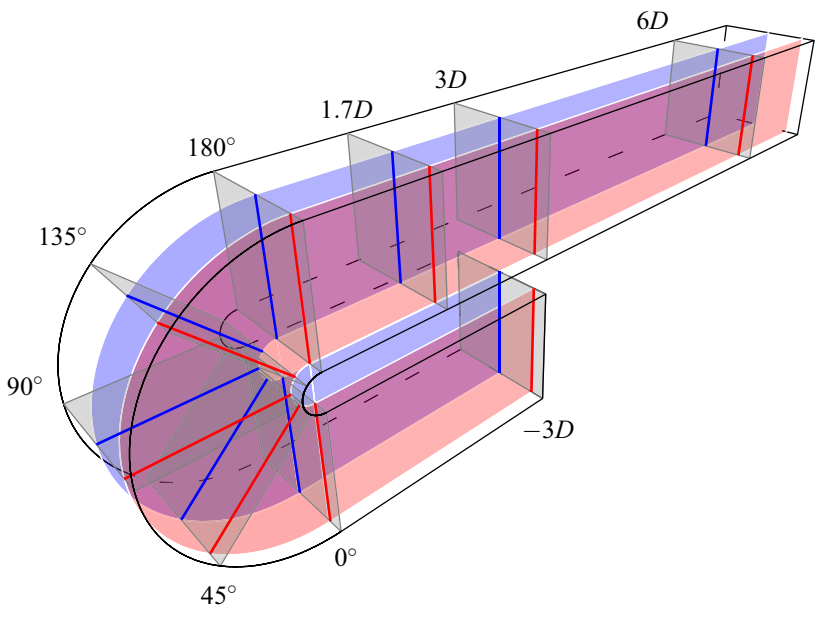

Fig. 6 U-duct. Locations where the flow characteristics are reported. The red and blue planes are the near-wall $\left(x_{1} / D=0.375\right)$ and center $\left(x_{1}=0\right)$ planes. The velocity profiles are reported along the red and blue lines. (Color figure online)

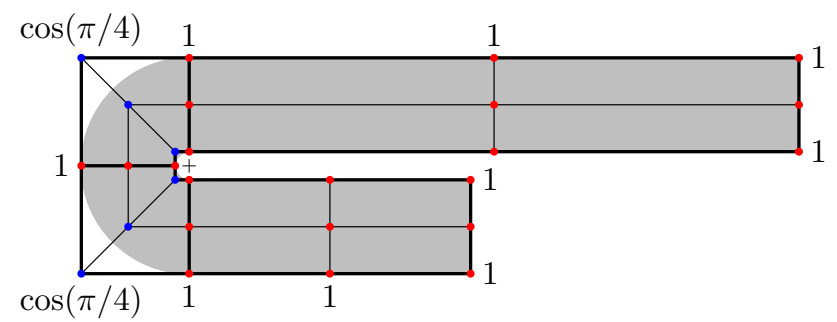

Fig. 7 U-duct. Exact representation of the curvature by NURBS. Weight definitions for the mesh. The blue points represent the control point locations where the weight is $\cos (\pi / 4)$, and the red points are where it is 1 . (Color figure online)

\subsection{Boundary conditions}

The ST-averaged velocity profile, $\overline{\overline{\mathbf{u}}}$, from the straight-duct computation is used as the inlet condition (see Sect. 3.5) The no-slip conditions on the walls are enforced weakly. At the outlet, zero-stress condition is used.

\subsection{Mesh}

To define the geometry exactly, we use four quadratic NURBS patches. Figure 7 shows the weight definitions. By using a sequence of knot insertions, we generate five meshes, which we call Mesh A, B, C, D and E. We start with Mesh A. Mesh B, C and D have in all three directions 2, 3 and 4 times the number of elements Mesh A has. Mesh E has along the bend twice the number of elements Mesh D has. Beyond that it has 5 more elements along the lower straight part of the duct, and the element sizes in both the lower and upper straight parts are adjusted along the streamwise direction such that the maximum ratio between two adjacent elements is at most 2. We note that Mesh D and E have the 
Table 1 U-duct. Number of control points $(n c)$, number of quadratic NURBS elements in the entire model $(n e)$ and along the bend $\left(n e_{\mathrm{b}}\right)$, streamwise length of the first element at the inlet $\left(h_{\mathrm{s} \text {, inlet }}\right)$, minimum streamwise element length $\left(h_{\mathrm{s}, \mathrm{min}}\right)$, which is in the bend, and $y^{+}$at the walls

\begin{tabular}{lllllr}
\hline Mesh & $n c$ & $n e$ & $n e_{\mathrm{b}}$ & $h_{\mathrm{s}, \text { inlet }}$ & $h_{\mathrm{s}, \text { min }}$ \\
\hline Mesh A & $20^{2} \times 60$ & $18^{2} \times 55$ & 12 & $2.77 \times 10^{-1} D$ & $3.6 \times 10^{-2} D$ \\
Mesh B & $38^{2} \times 115$ & $36^{2} \times 110$ & 24 & $1.39 \times 10^{-1} D$ & $1.8 \times 10^{-2} D$ \\
Mesh C & $56^{2} \times 170$ & $54^{2} \times 165$ & 36 & $0.93 \times 10^{-1} D$ & 1.90 \\
Mesh D & $74^{2} \times 225$ & $72^{2} \times 220$ & 48 & $0.69 \times 10^{-1} D$ & $1.2 \times 10^{-2} D$ \\
Mesh E & $74^{2} \times 278$ & $72^{2} \times 273$ & 96 & $0.69 \times 10^{-1} D$ & $0.9 \times 10^{-2} D$ \\
\hline
\end{tabular}
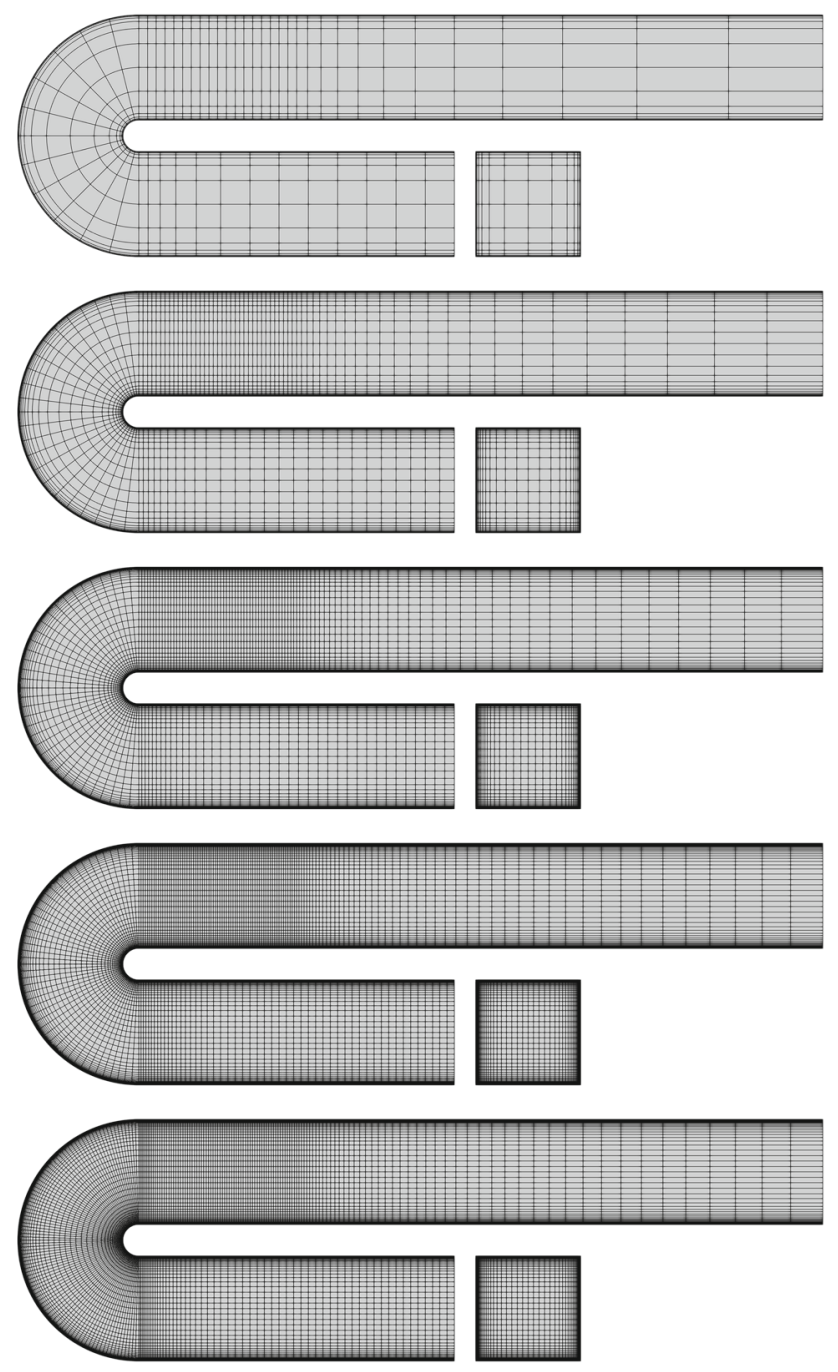

Fig. 8 U-duct. Mesh A, B, C, D and E

same cross-section as the straight-duct mesh in Sect. 3, and the same streamwise element length at the inlet. Figure 8 shows all five meshes, and Table 1 shows the mesh data for all five.

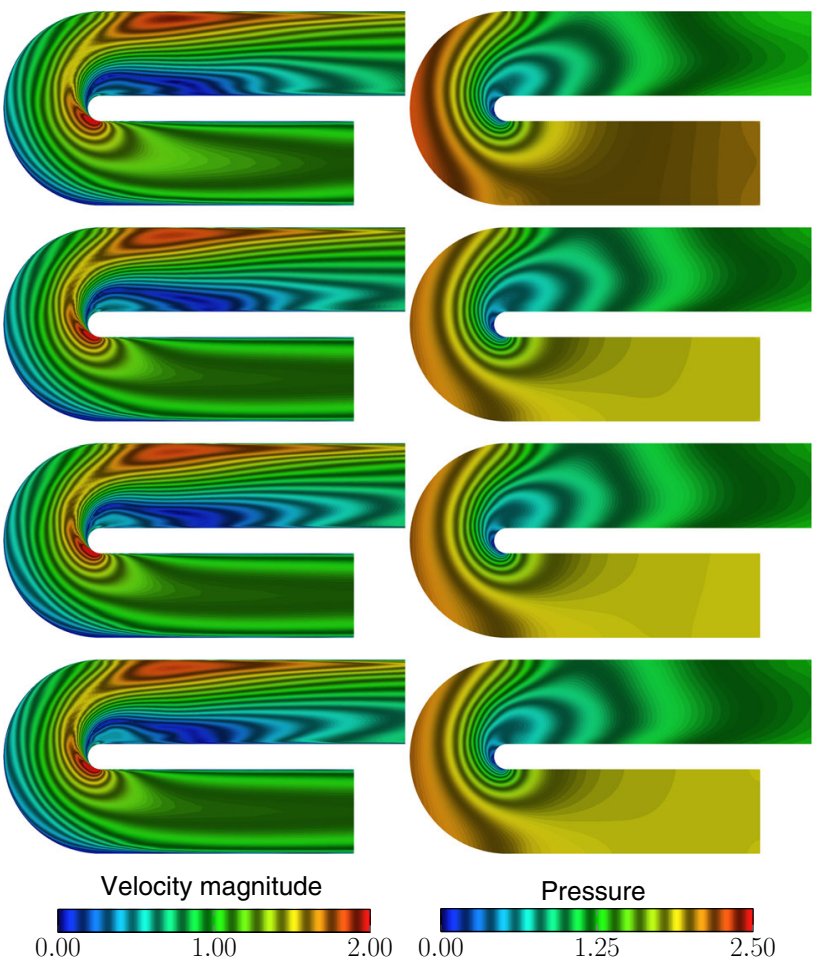

Fig. 9 U-duct. Flow development as depicted by $\|\overline{\mathbf{u}}\|$ and $\bar{p}$ on the center plane, for time-averaging over $\mathcal{T}=(0,10 T),(10 T, 20 T)$, $(20 T, 30 T)$, and $(30 T, 40 T)$

\subsection{Computational conditions}

We use the ST-VMS, with the stabilization parameters given by Eqs. (22)-(24), (33) and (34). The time-step size is determined from the Courant number, which is based on the minimum streamwise element length (see Table 1). The number of nonlinear iterations per time step is 3 , and the number of GMRES iterations per nonlinear iteration is 500. In calculating $T$ from $T=L / U$, we define $L=(3+0.65 \pi+6.5) D$. 


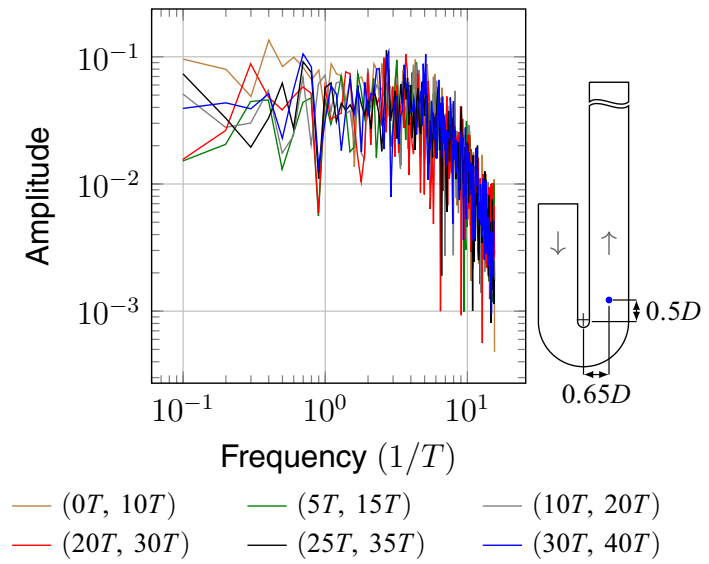

Fig. 10 U-duct. Fourier decomposition of $u_{2}$ at the blue point on the center plane, in the time ranges indicated in the legend, all spanning $10 T$. (Color figure online)

\subsection{Results}

\subsubsection{Sequence of computations}

First, Mesh A is used in computing for $\mathcal{T}=(0,40 T)$. Then, the initial condition for Mesh B computation is obtained by refining the data from Mesh A at $t=29 T$. After computing with Mesh B for a duration of $T$, the initial condition for Mesh $\mathrm{C}$ is obtained by least-squares projection at $t=30 T$. The initial conditions for Mesh $\mathrm{D}$ and $\mathrm{E}$ are also obtained by least-squares projection, from Mesh $\mathrm{C}$ at $t=31 T$ and from Mesh D at $t=32 T$.

\subsubsection{Effect of the time-averaging range}

In this study, we use $C_{\Delta t}=10$. Figure 9 shows the flow development as depicted by the flow patterns for different time-averaging ranges, all spanning 10T. The differences between the flow patterns for the time ranges beyond $\mathcal{T}=$ $(0,10 T)$ are not significant. Figure 10 shows the Fourier decomposition of $u_{2}$ in various time ranges, all spanning $10 T$. The patterns in the time ranges beyond $\mathcal{T}=(0,10 T)$ are similar. Figure 11 shows the Fourier decomposition of $u_{2}$ in various time ranges ending at $40 T$. We see that the lowest frequency of local maximum is around $0.67 T^{-1}$, which corresponds to a period of $1.5 T$. From that we conclude that an averaging period of $3 T$ is long enough in taking the statistics of the flow field.

\subsubsection{Effect of the mesh refinement}

We compare the data computed with Mesh $\mathrm{A}$ to $\mathrm{E}$ at $C_{\Delta t}=$ 10. Figure 12 shows the Fourier decomposition of $u_{2}$ in $\mathcal{T}=(33 T, 36 T)$. We see good agreement, though with the

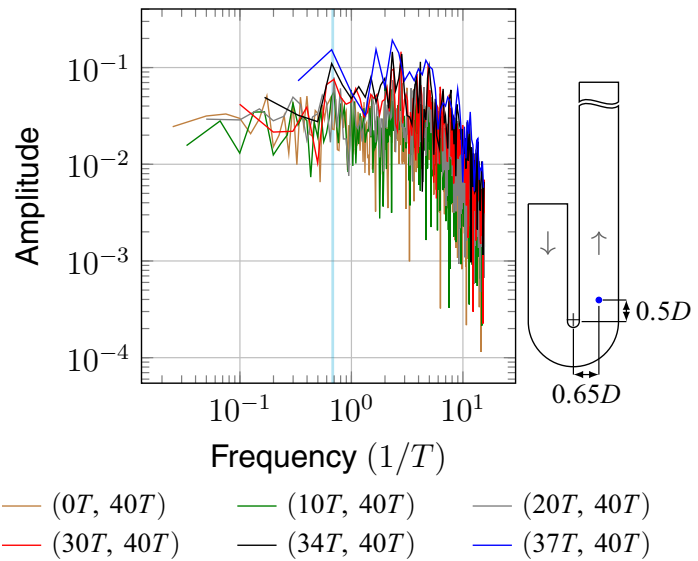

Fig. 11 U-duct. Fourier decomposition of $u_{2}$ at the blue point on the center plane, in the time ranges indicated in the legend, all ending at $40 T$. The cyan line marks the lowest frequency of local maximum. (Color figure online)

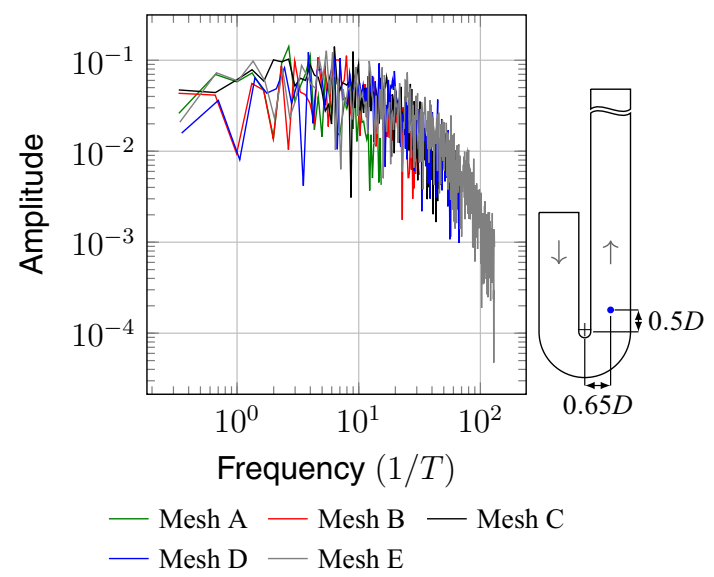

Fig. 12 U-duct. Fourier decomposition of $u_{2}$ at the blue point on the center plane, in $\mathcal{T}=(33 T, 36 T)$. (Color figure online)

representation getting shorter at the higher end of the spectrum as the mesh gets coarser. Figure 13 shows $\bar{u}_{\mathrm{s}}$ on the center plane, time-averaged over $\mathcal{T}=(33 T, 36 T)$, together with the experimental data from [188]. Slight effect of mesh refinement is seen between the results obtained with Mesh A and the finer meshes up to Mesh D, while the results obtained with Mesh B, C and D are in agreement. The results from Mesh E differ from the others slightly around the bend. Section 4.5.4 includes more investigation of the differences between the results obtained with Mesh D and E.

\subsubsection{Effect of the Courant number}

We compare the data computed with Mesh D and $\mathrm{E}$ at $C_{\Delta t}=$ 10,5 and 2.5 , in $\mathcal{T}=(33 T, 36 T)$. Figure 14 shows the isosurfaces corresponding to a positive value of the second invariant of $\nabla \overline{\mathbf{u}}$. With Mesh D, the effect of the Courant 
Fig. 13 U-duct. Effect of the mesh refinement. $\bar{u}_{\mathrm{s}}$ on the center plane, at various locations along the duct, time-averaged over $\mathcal{T}=(33 T, 36 T)$. The experimental data is from [188]
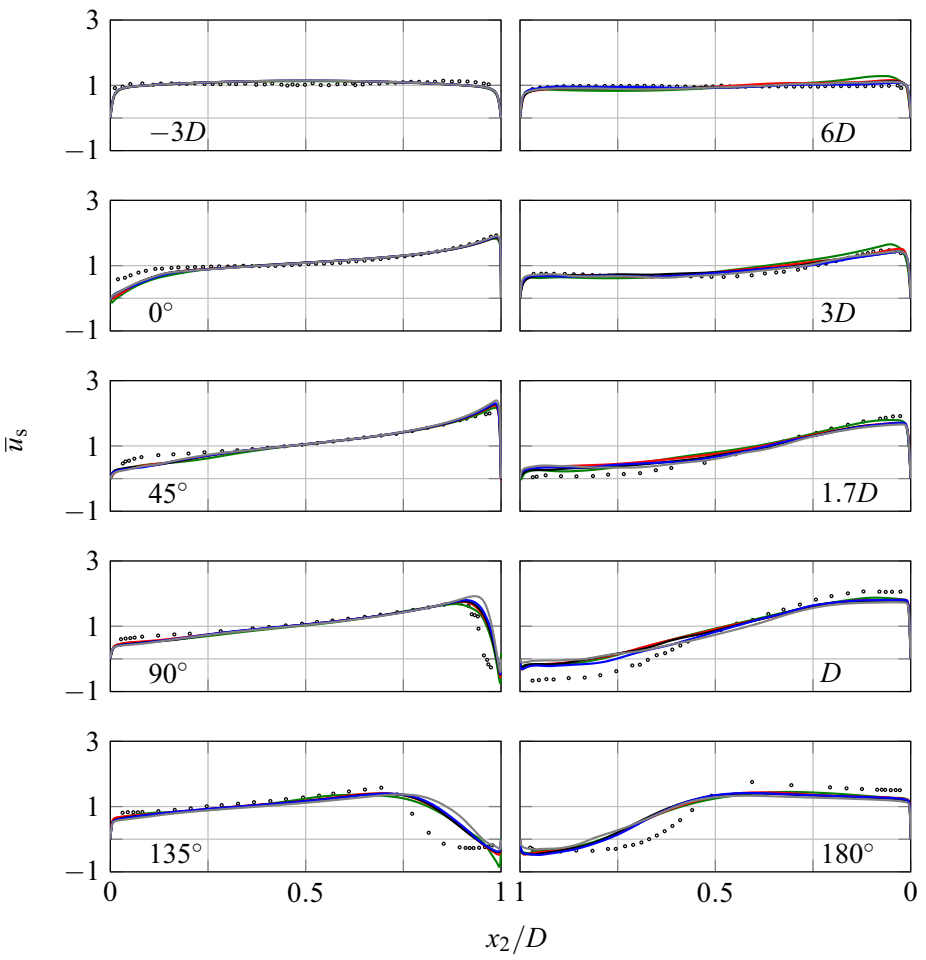

$$
\begin{array}{lll}
\text { - Mesh A } & - \text { Mesh B } & \text { - Mesh C } \\
\text { - Mesh D } & \text { Mesh E } & \text {. . Experim }
\end{array}
$$

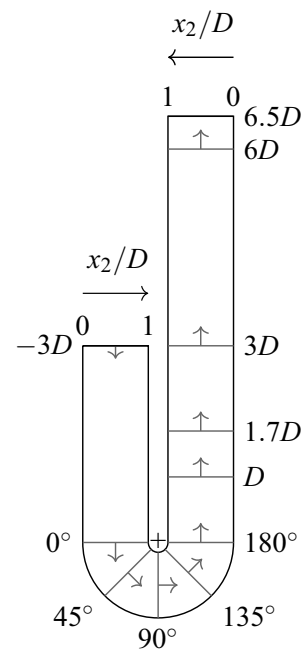

$x_{1}=0 D$

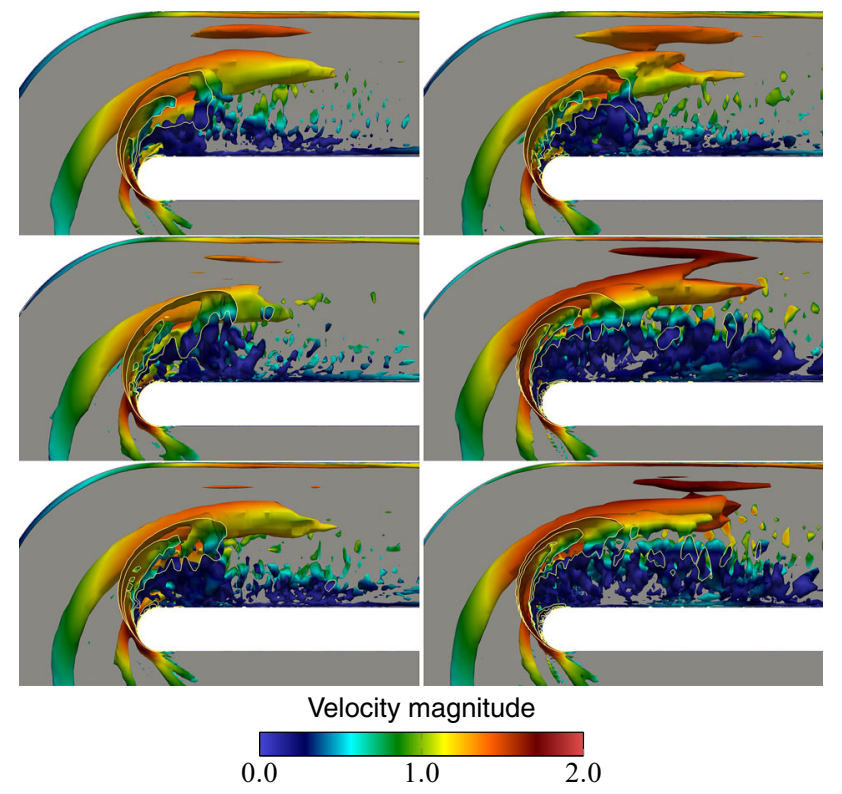

Fig. 14 U-duct. Isosurfaces corresponding to a positive value of the second invariant of $\boldsymbol{\nabla} \overline{\mathbf{u}}$, colored by $\|\overline{\mathbf{u}}\|$, time-averaged over $\mathcal{T}=$ $(33 T, 36 T)$. Mesh D (left) and $\mathrm{E}$ (right). $C_{\Delta t}=10$ (top), 5 (middle) and 2.5 (bottom). The yellow contour lines represent the intersection between the isosurfaces and the center plane. (Color figure online)

number is not significant. With Mesh $\mathrm{E}$ at $C_{\Delta t}=10$, the behavior is similar to what we see with Mesh D. On the other hand, with Mesh E at $C_{\Delta t}=5$ and 2.5, the recirculation occurs earlier. This observation becomes easier to make when we inspect $\bar{u}_{\mathrm{s}}$. Figures 15 and 16 show that, together with the experimental data from [188], on the center and near-wall planes. Figures 17 and 18 show $\left\|u_{\mathrm{s}}^{\prime}\right\|_{2, \mathcal{T}}$ on those planes. Overall, the data computed with Mesh E at $C_{\Delta t}=5$ and 2.5 is in good agreement with the experimental data.

\section{Concluding remarks}

We have conducted test and evaluation of the ST-VMS with ST isogeometric discretization in the benchmarking context of the U-duct turbulent flow, which has a number of computational challenges, and there is a good amount of experimental and computational data associated with this benchmark problem. The computational challenges include high Reynolds numbers, high curvature and strong flow dependence on the inflow profile. The ST framework provides higher-order accuracy in general, and the VMS feature of the ST-VMS addresses the computational challenges associated with the multiscale nature of the unsteady flow. The ST isogeometric discretization enables more accurate representation of the duct geometry and increased accuracy in the flow solution. We used the latest stabilization parameters designed in conjunction with the ST-VMS, with the latest element length expressions. The inflow velocity used in the computations 
comes from a fully-developed flow field in a straight-duct computation with periodicity condition, enforced with the ST-SI method. Both the straight-duct and U-duct computations were carried out with quadratic NURBS meshes, enabling exact representation of the circular arc in the U-duct computations. We investigated how the results vary with the averaging period used in reporting the results, mesh refinement, and the Courant number. We compared the results to experimental data and showed that the ST-VMS with ST isogeometric discretization provides good accuracy in this class of flow problems.

Acknowledgements This work was supported in part by Grant-in-Aid for Challenging Exploratory Research 16K13779 from Japan Society for the Promotion of Science; Grant-in-Aid for Scientific Research (S) 26220002 from the Ministry of Education, Culture, Sports, Science and Technology of Japan (MEXT); and Rice-Waseda research agreement. This work was also supported (first author) in part by YLSY scholarship program funded by the Republic of Turkey. The mathematical model and computational method parts of the work were also supported (third author) in part by ARO Grant W911NF-17-1-0046 and Top Global University Project of Waseda University.

Open Access This article is licensed under a Creative Commons Attribution 4.0 International License, which permits use, sharing, adaptation, distribution and reproduction in any medium or format, as long as you give appropriate credit to the original author(s) and the source, provide a link to the Creative Commons licence, and indicate if changes were made. The images or other third party material in this article are included in the article's Creative Commons licence, unless indicated otherwise in a credit line to the material. If material is not included in the article's Creative Commons licence and your intended use is not permitted by statutory regulation or exceeds the permitted use, you will need to obtain permission directly from the copyright holder. To view a copy of this licence, visit http://creativecomm ons.org/licenses/by/4.0/.

\section{A ST-VMS and ST-SI}

For completeness, we include, mostly from [106,135], the ST-VMS and ST-SI methods.

\section{A.1 ST-VMS}

The ST-VMS is given as

$$
\begin{aligned}
& \int_{Q_{n}} \mathbf{w}^{h} \cdot \rho\left(\frac{\partial \mathbf{u}^{h}}{\partial t}+\mathbf{u}^{h} \cdot \nabla \mathbf{u}^{h}-\mathbf{f}^{h}\right) \mathrm{d} Q \\
& \quad+\int_{Q_{n}} \boldsymbol{\varepsilon}\left(\mathbf{w}^{h}\right): \boldsymbol{\sigma}^{h} \mathrm{~d} Q-\int_{\left(P_{n}\right)_{\mathrm{h}}} \mathbf{w}^{h} \cdot \mathbf{h}^{h} \mathrm{~d} P \\
& \quad+\int_{Q_{n}} q^{h} \nabla \cdot \mathbf{u}^{h} \mathrm{~d} Q+\int_{\Omega_{n}}\left(\mathbf{w}^{h}\right)_{n}^{+} \cdot \rho\left(\left(\mathbf{u}^{h}\right)_{n}^{+}-\left(\mathbf{u}^{h}\right)_{n}^{-}\right) \mathrm{d} \Omega \\
& \quad+\sum_{e=1}^{\left(n_{\mathrm{el}}\right)_{n}} \int_{Q_{n}^{e}} \frac{\tau_{\mathrm{SUPS}}}{\rho}\left(\rho\left(\frac{\partial \mathbf{w}^{h}}{\partial t}+\mathbf{u}^{h} \cdot \nabla_{\mathbf{w}^{h}}\right)\right.
\end{aligned}
$$

$$
\begin{aligned}
& \left.+\nabla q^{h}\right) \cdot \mathbf{r}_{\mathrm{M}}^{h} \mathrm{~d} Q \\
& +\sum_{e=1}^{\left(n_{\mathrm{el}}\right)_{n}} \int_{Q_{n}^{e}} v_{\mathrm{LSIC}} \boldsymbol{\nabla} \cdot \mathbf{w}^{h} \rho r_{\mathrm{C}}^{h} \mathrm{~d} Q \\
& -\sum_{e=1}^{\left(n_{\mathrm{el}}\right)_{n}} \int_{Q_{n}^{e}} \tau_{\mathrm{SUPS}} \mathbf{w}^{h} \cdot\left(\mathbf{r}_{\mathrm{M}}^{h} \cdot \nabla \mathbf{u}^{h}\right) \mathrm{d} Q \\
& -\sum_{e=1}^{\left(n_{\mathrm{el}}\right)_{n}} \int_{Q_{n}^{e}} \frac{\tau_{\mathrm{SUPS}}^{2}}{\rho} \mathbf{r}_{\mathrm{M}}^{h} \cdot\left(\nabla \mathbf{w}^{h}\right) \cdot \mathbf{r}_{\mathrm{M}}^{h} \mathrm{~d} Q \\
& =0,
\end{aligned}
$$

where

$\mathbf{r}_{\mathrm{M}}^{h}=\rho\left(\frac{\partial \mathbf{u}^{h}}{\partial t}+\mathbf{u}^{h} \cdot \nabla \mathbf{u}^{h}-\mathbf{f}^{h}\right)-\nabla \cdot \boldsymbol{\sigma}^{h}$,

$r_{\mathrm{C}}^{h}=\nabla \cdot \mathbf{u}^{h}$

are the residuals of the momentum equation and incompressibility constraint. Here, $\mathbf{f}$ and $\mathbf{h}$ are the body force and the stress specified at the boundary. The stress tensor is defined as $\boldsymbol{\sigma}=-p \mathbf{I}+2 \mu \varepsilon(\mathbf{u})$, where $\mathbf{I}$ is the identity tensor and $\varepsilon(\mathbf{u})=\left((\nabla \mathbf{u})+(\nabla \mathbf{u})^{T}\right) / 2$ is the strain-rate tensor. The test functions associated with the $\mathbf{u}$ and $p$ are $\mathbf{w}$ and $q$. A superscript " $h$ " indicates that the function is coming from a finite-dimensional space. The symbol $Q_{n}$ represents the ST slice between time levels $n$ and $n+1,\left(P_{n}\right)_{\mathrm{h}}$ is the part of the slice lateral boundary associated with the boundary condition $\mathbf{h}$, and $\Omega_{n}$ is the spatial domain at time level $n$. The superscript " $e$ " is the ST element counter, and $n_{\mathrm{el}}$ is the number of ST elements. The functions are discontinuous in time at each time level, and the superscripts " -" and "+" indicate the values of the functions just below and above the time level.

Remark 1 The ST-SUPS can be obtained from the ST-VMS by dropping the eighth and ninth integrations.

The stabilization parameters, $\tau_{\text {SUPS }}$ and $\nu_{\text {LSIC }}$, will be given in Appendix B.1.

\section{A.2 ST-SI}

\section{A.2.1 Two-side formulation (fluid-fluid SI)}

In describing the ST-SI, labels "Side A" and "Side B" will represent the two sides of the SI. The ST-SI version of the formulation given by Eq. (14) includes added boundary terms corresponding to the SI. The boundary terms for the two sides are first added separately, using the test functions $\mathbf{w}_{\mathrm{A}}^{h}$ and $q_{\mathrm{A}}^{h}$ and $\mathbf{w}_{\mathrm{B}}^{h}$ and $q_{\mathrm{B}}^{h}$. Then, putting together the terms added to each side, the complete set of terms added becomes 
Fig. 15 U-duct. Effect of the Courant number for Mesh D and E. $\bar{u}_{\mathrm{s}}$ on the center plane, at various locations along the duct, time-averaged over

$\mathcal{T}=(33 T, 36 T)$. The

experimental data is from [188]

Fig. 16 U-duct. Effect of the Courant number for Mesh D and E. $\bar{u}_{\mathrm{S}}$ on the near-wall plane, at various locations along the duct, time-averaged over

$\mathcal{T}=(33 T, 36 T)$. The

experimental data is from [188]
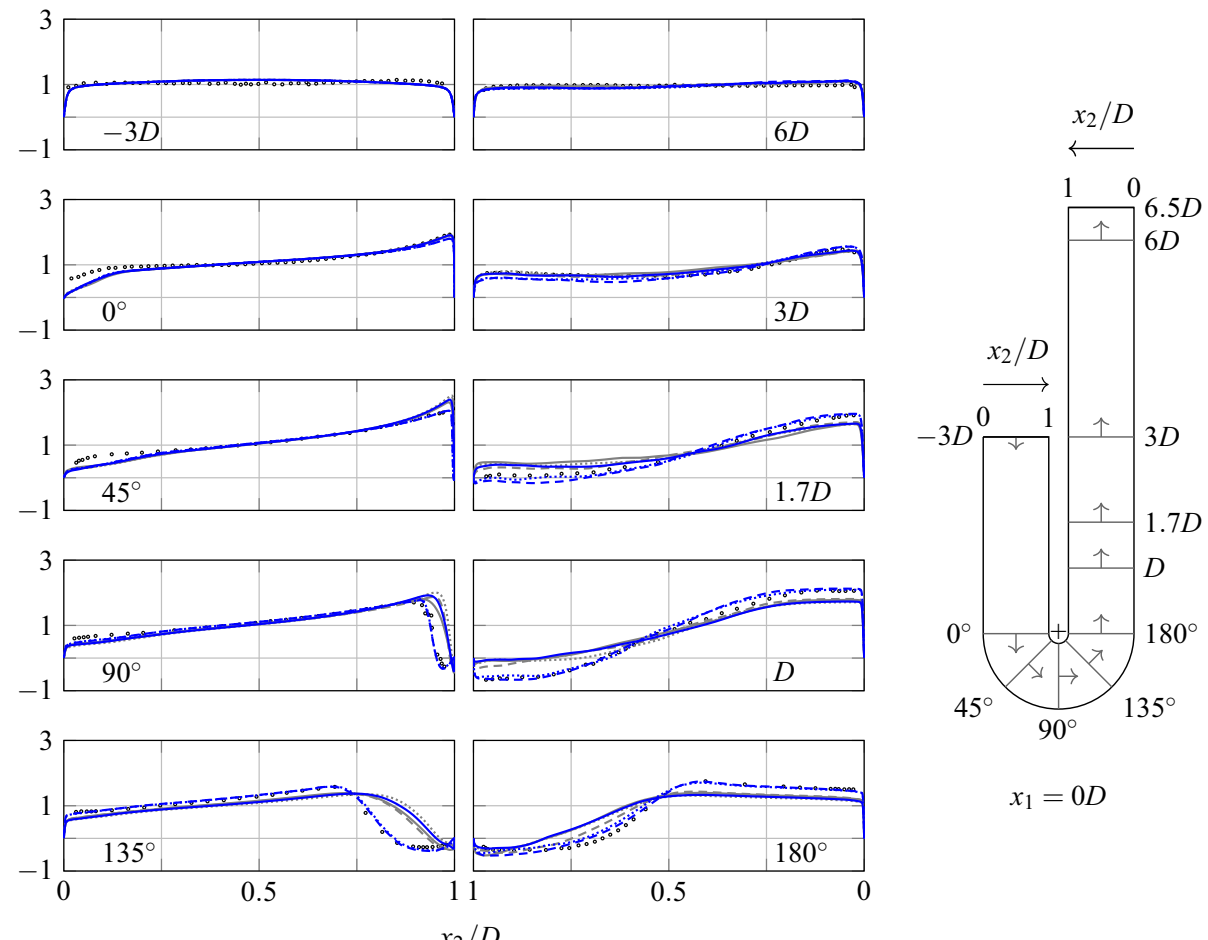

$x_{1}=0 D$

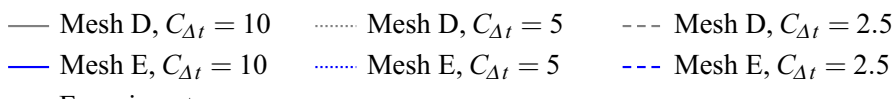

... Experiment
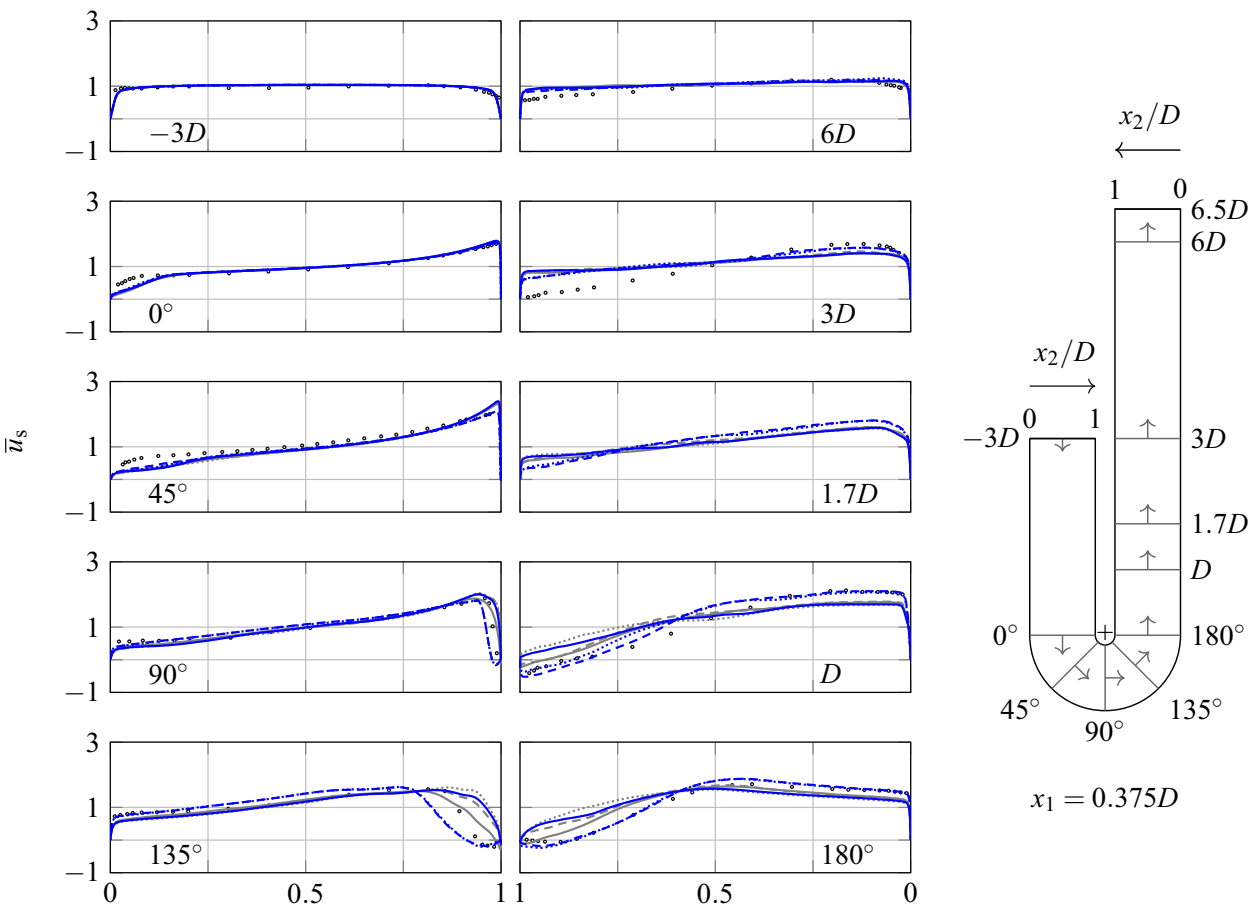

$x_{1}=0.375 D$

$x_{2} / D$

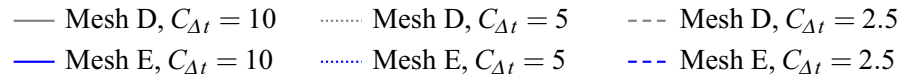

... Experiment 
Fig. 17 U-duct. Effect of the Courant number for Mesh D and E. $\left\|u_{\mathrm{s}}^{\prime}\right\|_{2, \mathcal{T}}$ on the center plane, at various locations along the duct, time-averaged over $\mathcal{T}=(33 T, 36 T)$. The experimental data is from [188]

Fig. 18 U-duct. Effect of the Courant number for Mesh D and E. $\left\|u_{\mathrm{s}}^{\prime}\right\|_{2, \mathcal{T}}$ on the near-wall plane, at various locations along the duct, time-averaged over $\mathcal{T}=(33 T, 36 T)$. The experimental data is from [188]
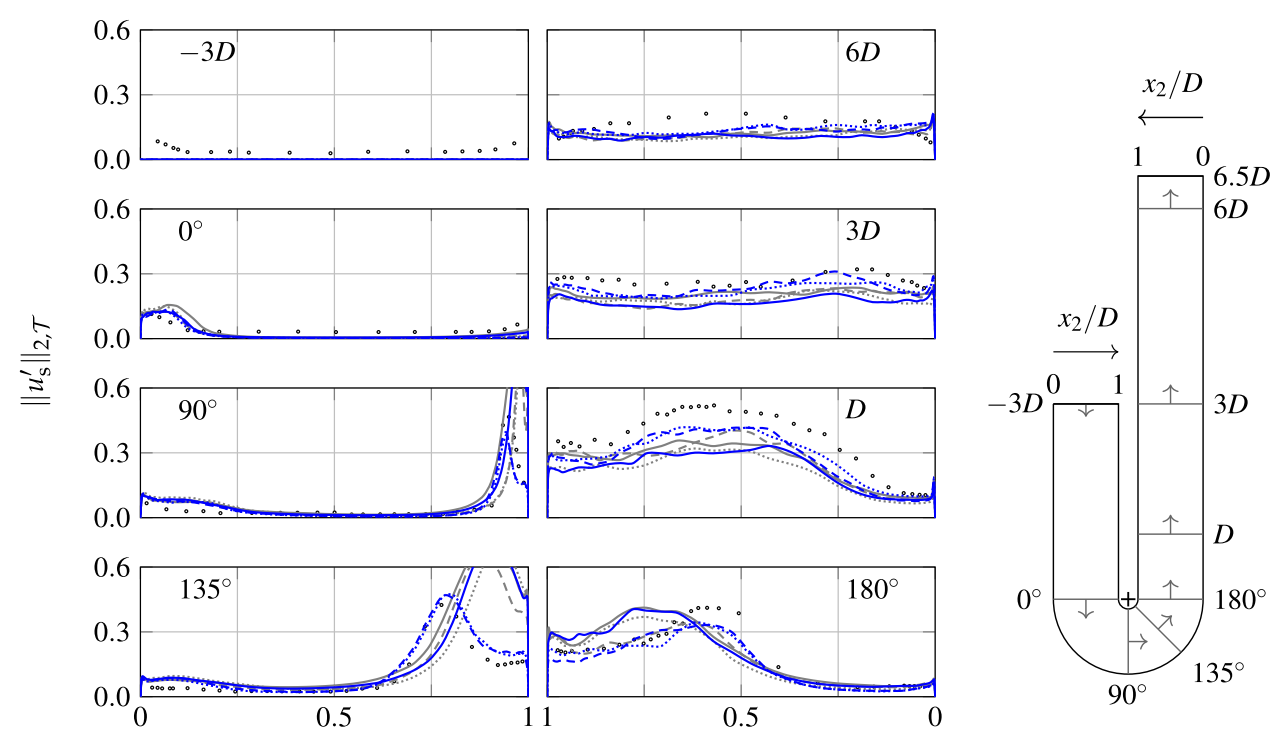

$x_{2} / D$

$x_{1}=0 D$

- Mesh D, $C_{\Delta t}=10 \quad$ ……. Mesh D, $C_{\Delta t}=5 \quad--$ Mesh D, $C_{\Delta t}=2.5$

- Mesh E, $C_{\Delta t}=10 \quad$-........ Mesh E, $C_{\Delta t}=5 \quad$-- Mesh E, $C_{\Delta t}=2.5$

$\cdots$ Experiment

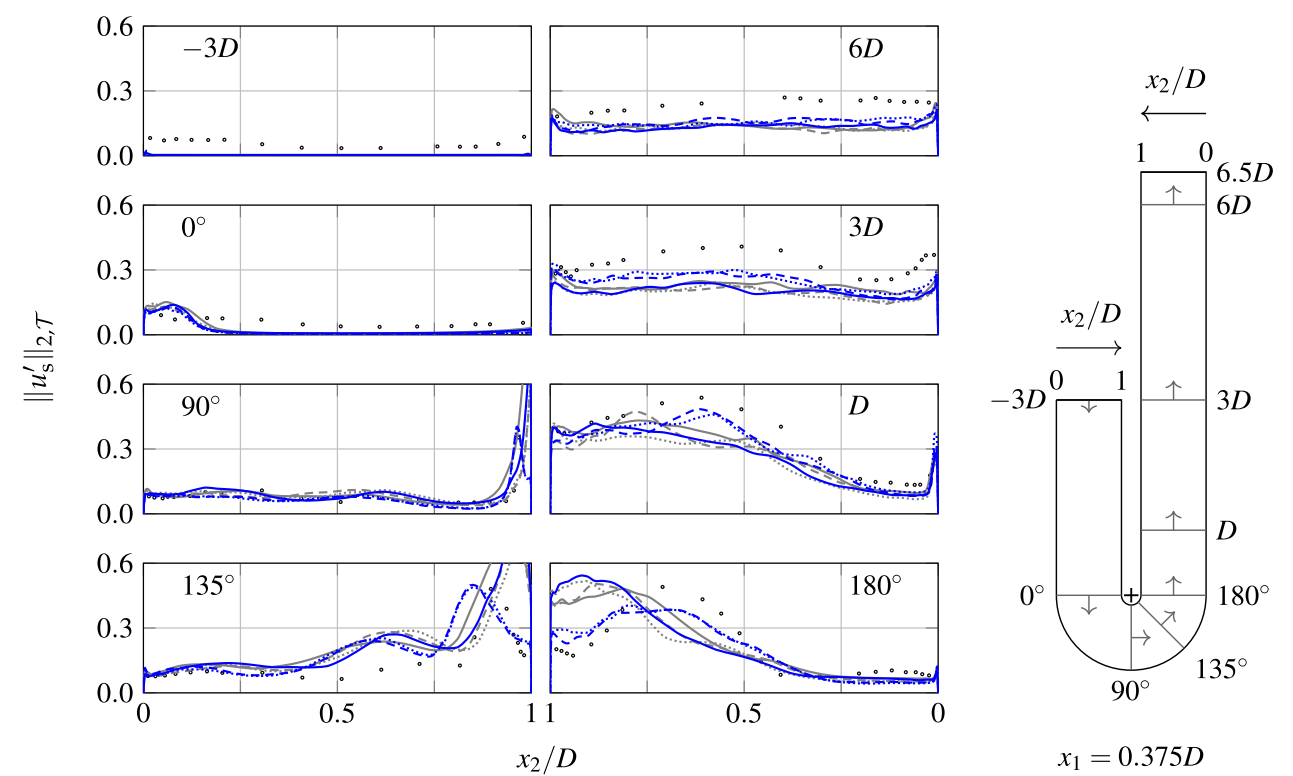

$$
\begin{array}{ll}
-\int_{\left(P_{n}\right)_{\mathrm{SI}}}\left(q_{\mathrm{B}}^{h} \mathbf{n}_{\mathrm{B}}-q_{\mathrm{A}}^{h} \mathbf{n}_{\mathrm{A}}\right) \cdot \frac{1}{2}\left(\mathbf{u}_{\mathrm{B}}^{h}-\mathbf{u}_{\mathrm{A}}^{h}\right) \mathrm{d} P & +\int_{\left(P_{n}\right)_{\mathrm{SI}}}\left(\mathbf{n}_{\mathrm{B}} \cdot \mathbf{w}_{\mathrm{B}}^{h}+\mathbf{n}_{\mathrm{A}} \cdot \mathbf{w}_{\mathrm{A}}^{h}\right) \frac{1}{2}\left(p_{\mathrm{B}}^{h}+p_{\mathrm{A}}^{h}\right) \mathrm{d} P \\
-\int_{\left(P_{n}\right)_{\mathrm{SI}}} \rho \mathbf{w}_{\mathrm{B}}^{h} \cdot \frac{1}{2}\left(\left(\mathcal{F}_{\mathrm{B}}^{h}-\left|\mathcal{F}_{\mathrm{B}}^{h}\right|\right) \mathbf{u}_{\mathrm{B}}^{h}\right. & -\int_{\left(P_{n}\right)_{\mathrm{SI}}}\left(\mathbf{n}_{\mathrm{B}} \cdot \mathbf{w}_{\mathrm{B}}^{h}-\mathbf{n}_{\mathrm{A}} \cdot \mathbf{w}_{\mathrm{A}}^{h}\right) \frac{1}{2} \Delta p \mathrm{~d} P \\
\left.-\left(\mathcal{F}_{\mathrm{B}}^{h}-\left|\mathcal{F}_{\mathrm{B}}^{h}\right|\right) \mathbf{u}_{\mathrm{A}}^{h}\right) \mathrm{d} P & -\int_{\left(P_{n}\right)_{\mathrm{SI}}}\left(\mathbf{w}_{\mathrm{B}}^{h}-\mathbf{w}_{\mathrm{A}}^{h}\right) \cdot\left(\hat{\mathbf{n}}_{\mathrm{B}} \cdot \mu\left(\varepsilon\left(\mathbf{u}_{\mathrm{B}}^{h}\right)+\varepsilon\left(\mathbf{u}_{\mathrm{A}}^{h}\right)\right)\right) \mathrm{d} P \\
-\int_{\left(P_{n}\right)_{\mathrm{SI}}} \rho \mathbf{w}_{\mathrm{A}}^{h} \cdot \frac{1}{2}\left(\left(\mathcal{F}_{\mathrm{A}}^{h}-\left|\mathcal{F}_{\mathrm{A}}^{h}\right|\right) \mathbf{u}_{\mathrm{A}}^{h}\right. & -\gamma \int_{\left(P_{n}\right)_{\mathrm{SI}}} \hat{\mathbf{n}}_{\mathrm{B}} \cdot \mu\left(\varepsilon\left(\mathbf{w}_{\mathrm{B}}^{h}+\boldsymbol{\varepsilon}\left(\mathbf{w}_{\mathrm{A}}^{h}\right)\right) \cdot\left(\mathbf{u}_{\mathrm{B}}^{h}-\mathbf{u}_{\mathrm{A}}^{h}\right) \mathrm{d} P\right. \\
\left.-\left(\mathcal{F}_{\mathrm{A}}^{h}-\left|\mathcal{F}_{\mathrm{A}}^{h}\right|\right) \mathbf{u}_{\mathrm{B}}^{h}\right) \mathrm{d} P &
\end{array}
$$




$$
+\int_{\left(P_{n}\right)_{\mathrm{SI}}} \frac{\mu C}{h}\left(\mathbf{w}_{\mathrm{B}}^{h}-\mathbf{w}_{\mathrm{A}}^{h}\right) \cdot\left(\mathbf{u}_{\mathrm{B}}^{h}-\mathbf{u}_{\mathrm{A}}^{h}\right) \mathrm{d} P,
$$

where

$$
\begin{aligned}
& \mathcal{F}_{\mathrm{B}}^{h}=\mathbf{n}_{\mathrm{B}} \cdot\left(\mathbf{u}_{\mathrm{B}}^{h}-\mathbf{v}_{\mathrm{B}}^{h}\right), \\
& \mathcal{F}_{\mathrm{A}}^{h}=\mathbf{n}_{\mathrm{A}} \cdot\left(\mathbf{u}_{\mathrm{A}}^{h}-\mathbf{v}_{\mathrm{A}}^{h}\right), \\
& \hat{\mathbf{n}}_{\mathrm{B}}=\frac{\mathbf{n}_{\mathrm{B}}-\mathbf{n}_{\mathrm{A}}}{\left\|\mathbf{n}_{\mathrm{B}}-\mathbf{n}_{\mathrm{A}}\right\|} .
\end{aligned}
$$

Here, $\left(P_{n}\right)_{\mathrm{SI}}$ is the SI in the ST domain, $\mathbf{n}$ is the unit normal vector, $\mathbf{v}$ is the mesh velocity, $\gamma=1$, and $C$ is a nondimensional constant. The element length $h$ will be defined in Appendix B.2. In Remark 3 of [135], it was proposed to use ST-SI also as a way of imposing the periodicity in ST-VMS computations with spatial periodicity. As mentioned in the same remark, in such cases, an SI is placed where the periodicity is imposed and the computations are carried out while including the corresponding ST-SI term. The fifth term in Eq. (17), with $\Delta p$ representing the pressure jump across the SI, is the ST-SI term corresponding to the periodicity. We note that, consistent with the notation in $[6,106,139,140]$, positive $\Delta p$ means higher pressure on Side A.

\section{A.2.2 One-side formulation (fluid-solid SI)}

On solid surfaces where we prefer weak enforcement of the Dirichlet conditions $[191,192]$ for the fluid, we use the ST-SI version where the SI is between the fluid and solid domains. This version is obtained (see [106]) by starting with the terms added to Side B and replacing the Side A velocity with the velocity $\mathbf{g}^{h}$ coming from the solid domain. Then the SI terms added to Eq. (14) to represent the weakly-enforced Dirichlet conditions become

$$
\begin{aligned}
& -\int_{\left(P_{n}\right)_{\mathrm{SI}}} q_{\mathrm{B}}^{h} \mathbf{n}_{\mathrm{B}} \cdot \mathbf{u}_{\mathrm{B}}^{h} \mathrm{~d} P \\
& -\int_{\left(P_{n}\right)_{\mathrm{SI}}} \rho \mathbf{w}_{\mathrm{B}}^{h} \cdot \mathcal{F}_{\mathrm{B}}^{h} \mathbf{u}_{\mathrm{B}}^{h} \mathrm{~d} P \\
& +\int_{\left(P_{n}\right)_{\mathrm{SI}}} q_{\mathrm{B}}^{h} \mathbf{n}_{\mathrm{B}} \cdot \mathbf{g}^{h} \mathrm{~d} P \\
& +\int_{\left(P_{n}\right)_{\mathrm{SI}}} \rho \mathbf{w}_{\mathrm{B}}^{h} \cdot \frac{1}{2}\left(\left(\mathcal{F}_{\mathrm{B}}^{h}+\left|\mathcal{F}_{\mathrm{B}}^{h}\right|\right) \mathbf{u}_{\mathrm{B}}^{h}\right. \\
& \left.+\left(\mathcal{F}_{\mathrm{B}}^{h}-\left|\mathcal{F}_{\mathrm{B}}^{h}\right|\right) \mathbf{g}^{h}\right) \mathrm{d} P \\
& -\int_{\left(P_{n}\right)_{\mathrm{SI}}} \mathbf{w}_{\mathrm{B}}^{h} \cdot\left(\mathbf{n}_{\mathrm{B}} \cdot \boldsymbol{\sigma}_{\mathrm{B}}^{h}\right) \mathrm{d} P \\
& -\gamma \int_{\left(P_{n}\right)_{\mathrm{SI}}} \mathbf{n}_{\mathrm{B}} \cdot 2 \mu \boldsymbol{\varepsilon}\left(\mathbf{w}_{\mathrm{B}}^{h}\right) \cdot\left(\mathbf{u}_{\mathrm{B}}^{h}-\mathbf{g}^{h}\right) \mathrm{d} P \\
& +\int_{\left(P_{n}\right)_{\mathrm{SI}}} \frac{\mu C}{h_{\mathrm{B}}} \mathbf{w}_{\mathrm{B}}^{h} \cdot\left(\mathbf{u}_{\mathrm{B}}^{h}-\mathbf{g}^{h}\right) \mathrm{d} P .
\end{aligned}
$$

The element length $h_{\mathrm{B}}$ will be given in Appendix B.2.

\section{B Stabilization parameters}

\section{B.1 ST-VMS}

There are various ways of defining the stabilization parameters $\tau_{\text {SUPS }}$ and $\nu_{\text {LSIC. }}$ Here, $\tau_{\text {SUPS }}$ is mostly from [185]:

$\tau_{\mathrm{SUPS}}=\left(\tau_{\mathrm{SUGN} 12}^{-2}+\tau_{\mathrm{SUGN} 3}^{-2}+\tau_{\mathrm{SUGN} 4}^{-2}\right)^{-\frac{1}{2}}$.

The first and second components are given as

$\tau_{\mathrm{SUGN} 12}^{-2}=\left[\begin{array}{l}1 \\ \mathbf{u}\end{array}\right]\left[\begin{array}{l}1 \\ \mathbf{u}\end{array}\right]: \mathbf{G}^{\mathrm{ST}}$

and

$\tau_{\mathrm{SUGN} 3}^{-1}=\nu \mathbf{r r}: \mathbf{G}$,

where $\mathbf{r}$ is the solution-gradient direction:

$\mathbf{r}=\frac{\nabla\|\mathbf{u}\|}{\|\nabla\| \mathbf{u}\|\|}$

Here $\mathbf{G}^{\mathrm{ST}}$ and $\mathbf{G}$ are the ST and space-only element metric tensors:

$$
\begin{aligned}
\mathbf{G}^{\mathrm{ST}} & =\left(\hat{\mathbf{Q}}^{\mathrm{ST}}\right)^{-T} \cdot\left(\hat{\mathbf{Q}}^{\mathrm{ST}}\right)^{-1}, \\
\mathbf{G} & =\hat{\mathbf{Q}}^{-T} \cdot \hat{\mathbf{Q}}^{-1},
\end{aligned}
$$

where

$$
\begin{aligned}
\hat{\mathbf{Q}}^{\mathrm{ST}} & =\mathbf{Q}^{\mathrm{ST}} \cdot\left(\mathbf{D}^{\mathrm{ST}}\right)^{-1}, \\
\hat{\mathbf{Q}} & =\mathbf{Q} \cdot \mathbf{D}^{-1} .
\end{aligned}
$$

The ST and space-only Jacobian tensors are

$\mathbf{Q}^{\mathrm{ST}}=\left[\begin{array}{ll}\frac{\partial t}{\partial \theta} & \frac{\partial t}{\partial \boldsymbol{\xi}} \\ \frac{\partial \mathbf{x}}{\partial \theta} & \mathbf{Q}\end{array}\right]$

and

$\mathbf{Q}=\frac{\partial \mathbf{x}}{\partial \boldsymbol{\xi}}$,

where $\theta$ and $\boldsymbol{\xi}$ are the temporal and spatial parametric coordinates. The transformation tensor $\mathbf{D}^{\mathrm{ST}}$ is defined as

$\mathbf{D}^{\mathrm{ST}}=\left[\begin{array}{cc}D_{\theta} & \mathbf{0}^{T} \\ \mathbf{0} & \mathbf{D}\end{array}\right]$. 
The definitions used for $D_{\theta}$ and $\mathbf{D}$ play an important role, especially for higher-order isogeometric discretization [10, 185] and simplex elements [186]. In this article, we set $D_{\theta}=$ 1 and set $\mathbf{D}$ to its "RQD-MAX" version [10].

The third component, originating from [3], is defined as

$\tau_{\mathrm{SUGN} 4}=\left\|\boldsymbol{\nabla} \mathbf{u}^{h}\right\|_{F}^{-1}$,

where $\|\cdot\|_{F}$ represents the Frobenius norm.

The stabilization parameter $v_{\text {LSIC }}$ is from [103]:

$\nu_{\mathrm{LSIC}}=\frac{h_{\mathrm{LSIC}}^{2}}{\tau_{\mathrm{SUPS}}}$

where $h_{\text {LSIC }}$ is set equal to the minimum element length $h_{\mathrm{MIN}}$ :

$h_{\mathrm{MIN}}=2\left(\max _{\mathbf{r}}(\mathbf{r r}: \mathbf{G})\right)^{-\frac{1}{2}}$.

For more ways of calculating the stabilization parameters in flow computations, see [73,167,172-183].

\section{B.2 ST-SI}

The element length used in the ST-SI is given as

$$
\begin{aligned}
h & =\left(\frac{h_{\mathrm{B}}^{-2}+h_{\mathrm{A}}^{-2}}{2}\right)^{-\frac{1}{2}}, \\
h_{\mathrm{B}} & =2\left(\mathbf{n}_{\mathrm{B}} \mathbf{n}_{\mathrm{B}}: \mathbf{G}\right)^{-\frac{1}{2}} \quad(\text { for Side B }), \\
h_{\mathrm{A}} & =2\left(\mathbf{n}_{\mathrm{A}} \mathbf{n}_{\mathrm{A}}: \mathbf{G}\right)^{-\frac{1}{2}} \quad(\text { for Side A }), \\
\hat{\mathbf{n}}_{\mathrm{B}} & =\frac{\mathbf{n}_{\mathrm{B}}-\mathbf{n}_{\mathrm{A}}}{\left\|\mathbf{n}_{\mathrm{B}}-\mathbf{n}_{\mathrm{A}}\right\|} .
\end{aligned}
$$

\section{References}

1. Takizawa K, Tezduyar TE (2011) Multiscale space-time fluidstructure interaction techniques. Comput Mech 48:247-267. https://doi.org/10.1007/s00466-011-0571-z

2. Takizawa K, Tezduyar TE (2012) Space-time fluidstructure interaction methods. Math Models Methods Appl Sci 22(supp02):1230001. https://doi.org/10.1142/ S0218202512300013

3. Takizawa K, Tezduyar TE, Kuraishi T (2015) Multiscale ST methods for thermo-fluid analysis of a ground vehicle and its tires. Math Models Methods Appl Sci 25:2227-2255. https://doi.org/ 10.1142/S0218202515400072

4. Takizawa K, Henicke B, Puntel A, Spielman T, Tezduyar TE (2012) Space-time computational techniques for the aerodynamics of flapping wings. J Appl Mech 79:010903. https://doi.org/10. $1115 / 1.4005073$
5. Takizawa K, Tezduyar TE, Otoguro Y, Terahara T, Kuraishi T, Hattori H (2017) Turbocharger flow computations with the spacetime isogeometric analysis (ST-IGA). Comput Fluids 142:15-20. https://doi.org/10.1016/j.compfluid.2016.02.021

6. Takizawa K, Tezduyar TE, Terahara T (2016) Ram-air parachute structural and fluid mechanics computations with the space-time isogeometric analysis (ST-IGA). Comput Fluids 141:191-200. https://doi.org/10.1016/j.compfluid.2016.05.027

7. Takizawa K, Henicke B, Montes D, Tezduyar TE, Hsu MC, Bazilevs Y (2011) Numerical-performance studies for the stabilized space-time computation of wind-turbine rotor aerodynamics. Comput Mech 48:647-657. https://doi.org/10.1007/ s00466-011-0614-5

8. Takizawa K, Montes D, McIntyre S, Tezduyar TE (2013) Spacetime VMS methods for modeling of incompressible flows at high Reynolds numbers. Math Models Methods Appl Sci 23:223-248. https://doi.org/10.1142/s0218202513400022

9. Kuraishi T, Takizawa K, Tezduyar TE (2019) Tire aerodynamics with actual tire geometry, road contact and tire deformation. Comput Mech 63:1165-1185. https://doi.org/10.1007/s00466018-1642-1

10. Otoguro Y, Takizawa K, Tezduyar TE (2020) Element length calculation in B-spline meshes for complex geometries. Comput Mech 65:1085-1103. https://doi.org/10.1007/s00466-01901809-w

11. Tezduyar TE (1992) Stabilized finite element formulations for incompressible flow computations. Adv Appl Mech 28:1-44. https://doi.org/10.1016/S0065-2156(08)70153-4

12. Tezduyar TE, Behr M, Liou J (1992) A new strategy for finite element computations involving moving boundaries and interfaces - the deforming-spatial-domain/space-time procedure: I. The concept and the preliminary numerical tests. Comput Methods Appl Mech Eng 94(3):339-351. https://doi.org/10.1016/ 0045-7825(92)90059-S

13. Tezduyar TE, Behr M, Mittal S, Liou J (1992) A new strategy for finite element computations involving moving boundaries and interfaces - the deforming-spatial-domain/space-time procedure: II. Computation of free-surface flows, two-liquid flows, and flows with drifting cylinders. Comput Methods Appl Mech Eng 94(3):353-371. https://doi.org/10.1016/0045-7825(92)90060-W

14. Hughes TJR, Brooks AN (1979) A multi-dimensional upwind scheme with no crosswind diffusion. In: Hughes TJR (ed) Finite element methods for convection dominated flows, AMD, vol 34. ASME, New York, pp 19-35

15. Brooks AN, Hughes TJR (1982) Streamline upwind/PetrovGalerkin formulations for convection dominated flows with particular emphasis on the incompressible Navier-Stokes equations. Comput Methods Appl Mech Eng 32:199-259

16. Tezduyar TE, Hughes TJR (1982) Development of time-accurate finite element techniques for first-order hyperbolic systems with particular emphasis on the compressible Euler equations. NASA technical report NASA-CR-204772. NASA. http://www. researchgate.net/publication/24313718/

17. Tezduyar TE, Hughes TJR (1983) Finite element formulations for convection dominated flows with particular emphasis on the compressible Euler equations. In: Proceedings of AIAA 21st aerospace sciences meeting, AIAA paper 83-0125, Reno, Nevada. https://doi.org/10.2514/6.1983-125

18. Hughes TJR, Tezduyar TE (1984) Finite element methods for first-order hyperbolic systems with particular emphasis on the compressible Euler equations. Comput Methods Appl Mech Eng 45:217-284. https://doi.org/10.1016/0045-7825(84)90157-9

19. Tezduyar TE, Mittal S, Ray SE, Shih R (1992) Incompressible flow computations with stabilized bilinear and linear equalorder-interpolation velocity-pressure elements. Comput Meth- 
ods Appl Mech Eng 95:221-242. https://doi.org/10.1016/00457825(92)90141-6

20. Hughes TJR, Franca LP, Balestra M (1986) A new finite element formulation for computational fluid dynamics: V. Circumventing the Babuška-Brezzi condition: A stable Petrov-Galerkin formulation of the Stokes problem accommodating equal-order interpolations. Comput Methods Appl Mech Eng 59:85-99

21. Hughes TJR (1995) Multiscale phenomena: Green's functions, the Dirichlet-to-Neumann formulation, subgrid scale models, bubbles, and the origins of stabilized methods. Comput Methods Appl Mech Eng 127:387-401

22. Hughes TJR, Oberai AA, Mazzei L (2001) Large eddy simulation of turbulent channel flows by the variational multiscale method. Phys Fluids 13:1784-1799

23. Bazilevs Y, Calo VM, Cottrell JA, Hughes TJR, Reali A, Scovazzi G (2007) Variational multiscale residual-based turbulence modeling for large eddy simulation of incompressible flows. Comput Methods Appl Mech Eng 197:173-201

24. Bazilevs Y, Akkerman I (2010) Large eddy simulation of turbulent Taylor-Couette flow using isogeometric analysis and the residualbased variational multiscale method. J Comput Phys 229:34023414

25. Hughes TJR, Liu WK, Zimmermann TK (1981) LagrangianEulerian finite element formulation for incompressible viscous flows. Comput Methods Appl Mech Eng 29:329-349

26. Bazilevs Y, Calo VM, Hughes TJR, Zhang Y (2008) Isogeometric fluid-structure interaction: theory, algorithms, and computations. Comput Mech 43:3-37

27. Takizawa K, Bazilevs Y, Tezduyar TE (2012) Space-time and ALE-VMS techniques for patient-specific cardiovascular fluidstructure interaction modeling. Arch Comput Methods Eng 19:171-225. https://doi.org/10.1007/s11831-012-9071-3

28. Bazilevs Y, Hsu M-C, Takizawa K, Tezduyar TE (2012) ALEVMS and ST-VMS methods for computer modeling of windturbine rotor aerodynamics and fluid-structure interaction. Math Models Methods Appl Sci 22(supp02):1230002. https://doi.org/ 10.1142/S0218202512300025

29. Bazilevs Y, Takizawa K, Tezduyar TE (2013) Computational fluid-structure interaction: methods and applications. Wiley, Hoboken ISBN 978-0470978771

30. Bazilevs Y, Takizawa K, Tezduyar TE (2013) Challenges and directions in computational fluid-structure interaction. Math Models Methods Appl Sci 23:215-221. https://doi.org/10.1142/ S0218202513400010

31. Bazilevs Y, Takizawa K, Tezduyar TE (2015) New directions and challenging computations in fluid dynamics modeling with stabilized and multiscale methods. Math Models Methods Appl Sci 25:2217-2226. https://doi.org/10.1142/S0218202515020029

32. Bazilevs Y, Takizawa K, Tezduyar TE (2019) Computational analysis methods for complex unsteady flow problems. Math Models Methods Appl Sci 29:825-838. https://doi.org/10.1142/ S0218202519020020

33. Kalro V, Tezduyar TE (2000) A parallel 3D computational method for 1fluid-structure interactions in parachute systems. Comput Methods Appl Mech Eng 190:321-332. https://doi.org/10.1016/ S0045-7825(00)00204-8

34. Bazilevs Y, Hsu M-C, Akkerman I, Wright S, Takizawa K, Henicke B, Spielman T, Tezduyar TE (2011) 3D simulation of wind turbine rotors at full scale. Part I: geometry modeling and aerodynamics. Int J Numer Meth Fluids 65:207-235. https://doi. org/10.1002/fld. 2400

35. Bazilevs Y, Hsu M-C, Kiendl J, Wüchner R, Bletzinger K-U (2011) 3D simulation of wind turbine rotors at full scale. Part II: fluid-structure interaction modeling with composite blades. Int J Numer Meth Fluids 65:236-253
36. Hsu M-C, Akkerman I, Bazilevs Y (2011) High-performance computing of wind turbine aerodynamics using isogeometric analysis. Comput Fluids 49:93-100

37. Bazilevs Y, Hsu M-C, Scott MA (2012) Isogeometric fluidstructure interaction analysis with emphasis on non-matching discretizations, and with application to wind turbines. Comput Methods Appl Mech Eng 249-252:28-41

38. Hsu M-C, Akkerman I, Bazilevs Y (2014) Finite element simulation of wind turbine aerodynamics: validation study using NREL Phase VI experiment. Wind Energy 17:461-481

39. Korobenko A, Hsu M-C, Akkerman I, Tippmann J, Bazilevs Y (2013) Structural mechanics modeling and FSI simulation of wind turbines. Math Models Methods Appl Sci 23:249-272

40. Bazilevs Y, Takizawa K, Tezduyar TE, Hsu M-C, Kostov N, McIntyre S (2014) Aerodynamic and FSI analysis of wind turbines with the ALE-VMS and ST-VMS methods. Arch Comput Methods Eng 21:359-398. https://doi.org/10.1007/s11831-014-9119-7

41. Bazilevs Y, Korobenko A, Deng X, Yan J (2015) Novel structural modeling and mesh moving techniques for advanced FSI simulation of wind turbines. Int J Numer Meth Eng 102:766-783. https:// doi.org/10.1002/nme.4738

42. Korobenko A, Yan J, Gohari SMI, Sarkar S, Bazilevs Y (2017) FSI simulation of two back-to-back wind turbines in atmospheric boundary layer flow. Comput Fluids 158:167-175. https://doi.org/ 10.1016/j.compfluid.2017.05.010

43. Korobenko A, Bazilevs Y, Takizawa K, Tezduyar TE (2018) Recent advances in ALE-VMS and ST-VMS computational aerodynamic and FSI analysis of wind turbines. In: Tezduyar TE (ed) Frontiers in computational fluid-structure interaction and flow simulation: research from lead investigators under forty-2018, modeling and simulation in science, engineering and technology. Springer, pp 253-336. ISBN 978-3-319-96468-3. https://doi.org/ 10.1007/978-3-319-96469-0_7

44. Korobenko A, Bazilevs Y, Takizawa K, Tezduyar TE (2019) Computer modeling of wind turbines: 1. ALE-VMS and STVMS aerodynamic and FSI analysis. Arch Comput Methods Eng 26:1059-1099. https://doi.org/10.1007/s11831-018-9292-1

45. Bazilevs Y, Takizawa K, Tezduyar TE, Hsu M-C, Otoguro Y, Mochizuki H, Wu MCH (2020) Wind turbine and turbomachinery computational analysis with the ALE and space-time variational multiscale methods and isogeometric discretization. J Adv Eng Comput 4:1-32. https://doi.org/10.25073/jaec.202041.278

46. Bazilevs Y, Takizawa K, Tezduyar TE, Hsu M-C, Otoguro Y, Mochizuki H, Wu MCH (2020) ALE and space-time variational multiscale isogeometric analysis of wind turbines and turbomachinery. In: Grama A, Sameh A (eds) Parallel algorithms in computational science and engineering, modeling and simulation in science, engineering and technology. Springer, pp 195-233. ISBN 978-3-030-43735-0. https://doi.org/10.1007/ 978-3-030-43736-7_7

47. Korobenko A, Hsu M-C, Akkerman I, Bazilevs Y (2013) Aerodynamic simulation of vertical-axis wind turbines. J Appl Mech 81:021011. https://doi.org/10.1115/1.4024415

48. Bazilevs Y, Korobenko A, Deng X, Yan J, Kinzel M, Dabiri JO (2014) FSI modeling of vertical-axis wind turbines. J Appl Mech 81:081006. https://doi.org/10.1115/1.4027466

49. Yan J, Korobenko A, Deng X, Bazilevs Y (2016) Computational free-surface fluid-structure interaction with application to floating offshore wind turbines. Comput Fluids 141:155-174. https://doi. org/10.1016/j.compfluid.2016.03.008

50. Bazilevs Y, Korobenko A, Yan J, Pal A, Gohari SMI, Sarkar S (2015) ALE-VMS formulation for stratified turbulent incompressible flows with applications. Math Models Methods Appl Sci 25:2349-2375. https://doi.org/10.1142/S0218202515400114

51. Takizawa K, Bazilevs Y, Tezduyar TE, Korobenko A (2020) Variational multiscale flow analysis in aerospace, energy and 
transportation technologies. J Adv Eng Comput 4:83-117. https:// doi.org/10.25073/jaec.202042.279

52. Takizawa K, Bazilevs Y, Tezduyar TE, Korobenko A (2020) Variational multiscale flow analysis in aerospace, energy and transportation technologies. In: Grama A, Sameh A (eds) Parallel algorithms in computational science and engineering, modeling and simulation in science, engineering and technology. Springer, pp 235-280. ISBN 978-3-030-43735-0. https://doi.org/10.1007/ 978-3-030-43736-7_8

53. Bazilevs Y, Korobenko A, Deng X, Yan J (2016) FSI modeling for fatigue-damage prediction in full-scale wind-turbine blades. $\mathrm{J}$ Appl Mech 83(6):061010

54. Bazilevs Y, Calo VM, Zhang Y, Hughes TJR (2006) Isogeometric fluid-structure interaction analysis with applications to arterial blood flow. Comput Mech 38:310-322

55. Bazilevs Y, Gohean JR, Hughes TJR, Moser RD, Zhang Y (2009) Patient-specific isogeometric fluid-structure interaction analysis of thoracic aortic blood flow due to implantation of the Jarvik (2000) left ventricular assist device. Comput Methods Appl Mech Eng 198:3534-3550

56. Bazilevs Y, Hsu M-C, Benson D, Sankaran S, Marsden A (2009) Computational fluid-structure interaction: methods and application to a total cavopulmonary connection. Comput Mech 45:77-89

57. Bazilevs Y, Hsu M-C, Zhang Y, Wang W, Liang X, Kvamsdal T, Brekken R, Isaksen J (2010) A fully-coupled fluid-structure interaction simulation of cerebral aneurysms. Comput Mech 46:3-16

58. Bazilevs Y, Hsu M-C, Zhang Y, Wang W, Kvamsdal T, Hentschel S, Isaksen J (2010) Computational fluid-structure interaction: methods and application to cerebral aneurysms. Biomech Model Mechanobiol 9:481-498

59. Hsu M-C, Bazilevs Y (2011) Blood vessel tissue prestress modeling for vascular fluid-structure interaction simulations. Finite Elem Anal Des 47:593-599

60. Long CC, Marsden AL, Bazilevs Y (2013) Fluid-structure interaction simulation of pulsatile ventricular assist devices. Comput Mech 52:971-981. https://doi.org/10.1007/s00466-013-0858-3

61. Long CC, Esmaily-Moghadam M, Marsden AL, Bazilevs Y (2014) Computation of residence time in the simulation of pulsatile ventricular assist devices. Comput Mech 54:911-919. https://doi.org/10.1007/s00466-013-0931-y

62. Long CC, Marsden AL, Bazilevs Y (2014) Shape optimization of pulsatile ventricular assist devices using FSI to minimize thrombotic risk. Comput Mech 54:921-932. https://doi.org/10.1007/ s00466-013-0967-z

63. Hsu M-C, Kamensky D, Bazilevs Y, Sacks MS, Hughes TJR (2014) Fluid-structure interaction analysis of bioprosthetic heart valves: significance of arterial wall deformation. Comput Mech 54:1055-1071. https://doi.org/10.1007/s00466-014-1059-4

64. Hsu M-C, Kamensky D, Xu F, Kiendl J, Wang C, Wu MCH, Mineroff J, Reali A, Bazilevs Y, Sacks MS (2015) Dynamic and fluid-structure interaction simulations of bioprosthetic heart valves using parametric design with T-splines and Fung-type material models. Comput Mech 55:1211-1225. https://doi.org/ 10.1007/s00466-015-1166-x

65. Kamensky D, Hsu M-C, Schillinger D, Evans JA, Aggarwal A, Bazilevs Y, Sacks MS, Hughes TJR (2015) An immersogeometric variational framework for fluid-structure interaction: application to bioprosthetic heart valves. Comput Methods Appl Mech Eng 284:1005-1053

66. Takizawa K, Bazilevs Y, Tezduyar TE, Hsu M-C (2019) Computational cardiovascular flow analysis with the variational multiscale methods. J Adv Eng Comput 3:366-405. https://doi.org/10. 25073/jaec.201932.245

67. Hughes TJR, Takizawa K, Bazilevs Y, Tezduyar TE, Hsu M-C (2020) Computational cardiovascular analysis with the variational multiscale methods and isogeometric discretization. In: Grama
A, Sameh A (eds) Parallel algorithms in computational science and engineering, modeling and simulation in science, engineering and technology. Springer, pp 151-193. ISBN 978-3-030-43735-0. https://doi.org/10.1007/978-3-030-43736-7_6

68. Akkerman I, Bazilevs Y, Benson DJ, Farthing MW, Kees CE (2012) Free-surface flow and fluid-object interaction modeling with emphasis on ship hydrodynamics. J Appl Mech 79:010905

69. Akkerman I, Dunaway J, Kvandal J, Spinks J, Bazilevs Y (2012) Toward free-surface modeling of planing vessels: simulation of the Fridsma hull using ALE-VMS. Comput Mech 50:719-727

70. Wang C, Wu MCH, Xu F, Hsu M-C, Bazilevs Y (2017) Modeling of a hydraulic arresting gear using fluid-structure interaction and isogeometric analysis. Comput Fluids 142:3-14. https://doi.org/ 10.1016/j.compfluid.2015.12.004

71. Wu MCH, Kamensky D, Wang C, Herrema AJ, Xu F, Pigazzini MS, Verma A, Marsden AL, Bazilevs Y, Hsu M-C (2017) Optimizing fluid-structure interaction systems with immersogeometric analysis and surrogate modeling: application to a hydraulic arresting gear. Comput Methods Appl Mech Eng 316:668-693

72. Yan J, Deng X, Korobenko A, Bazilevs Y (2017) Free-surface flow modeling and simulation of horizontal-axis tidal-stream turbines. Comput Fluids 158:157-166. https://doi.org/10.1016/ j.compfluid.2016.06.016

73. Castorrini A, Corsini A, Rispoli F, Takizawa K, Tezduyar TE (2019) A stabilized ALE method for computational fluidstructure interaction analysis of passive morphing in turbomachinery. Math Models Methods Appl Sci 29:967-994. https://doi. org/10.1142/S0218202519410057

74. Augier B, Yan J, Korobenko A, Czarnowski J, Ketterman G, Bazilevs Y (2015) Experimental and numerical FSI study of compliant hydrofoils. Comput Mech 55:1079-1090. https://doi.org/ 10.1007/s00466-014-1090-5

75. Yan J, Augier B, Korobenko A, Czarnowski J, Ketterman G, Bazilevs Y (2016) FSI modeling of a propulsion system based on compliant hydrofoils in a tandem configuration. Comput Fluids 141:201-211. https://doi.org/10.1016/j.compfluid.2015.07.013

76. Helgedagsrud TA, Bazilevs Y, Mathisen KM, Oiseth OA (2019) Computational and experimental investigation of free vibration and flutter of bridge decks. Comput Mech 63:121-136. https:// doi.org/10.1007/s00466-018-1587-4

77. Helgedagsrud TA, Bazilevs Y, Korobenko A, Mathisen KM, Oiseth OA (2019) Using ALE-VMS to compute aerodynamic derivatives of bridge sections. Comput Fluids 179:820-832. https://doi.org/10.1016/j.compfluid.2018.04.037

78. Helgedagsrud TA, Akkerman I, Bazilevs Y, Mathisen KM, Oiseth OA (2019) Isogeometric modeling and experimental investigation of moving-domain bridge aerodynamics. ASCE J Eng Mech 145:04019026. https://doi.org/10.1061/(ASCE)EM.19437889.0001601

79. Kamensky D, Evans JA, Hsu M-C, Bazilevs Y (2017) Projectionbased stabilization of interface Lagrange multipliers in immersogeometric fluid-thin structure interaction analysis, with application to heart valve modeling. Comput Math Appl 74:2068-2088. https://doi.org/10.1016/j.camwa.2017.07.006

80. Yu Y, Kamensky D, Hsu M-C, Lu XY, Bazilevs Y, Hughes TJR (2018) Error estimates for projection-based dynamic augmented Lagrangian boundary condition enforcement, with application to fluid-structure interaction. Math Models Methods Appl Sci 28:2457-2509. https://doi.org/10.1142/S0218202518500537

81. Tezduyar TE, Takizawa K, Moorman C, Wright S, Christopher J (2010) Space-time finite element computation of complex fluidstructure interactions. Int J Numer Meth Fluids 64:1201-1218. https://doi.org/10.1002/fld.2221

82. Yan J, Korobenko A, Tejada-Martinez AE, Golshan R, Bazilevs $\mathrm{Y}$ (2017) A new variational multiscale formulation for strati- 
fied incompressible turbulent flows. Comput Fluids 158:150-156. https://doi.org/10.1016/j.compfluid.2016.12.004

83. van Opstal TM, Yan J, Coley C, Evans JA, Kvamsdal T, Bazilevs Y (2017) Isogeometric divergence-conforming variational multiscale formulation of incompressible turbulent flows. Comput Methods Appl Mech Eng 316:859-879. https://doi.org/10.1016/ j.cma.2016.10.015

84. Xu F, Moutsanidis G, Kamensky D, Hsu M-C, Murugan M, Ghoshal A, Bazilevs Y (2017) Compressible flows on moving domains: stabilized methods, weakly enforced essential boundary conditions, sliding interfaces, and application to gas-turbine modeling. Comput Fluids 158:201-220. https://doi.org/10.1016/ j.compfluid.2017.02.006

85. Bazilevs Y, Takizawa K, Wu MCH, Kuraishi T, Avsar R, Xu Z, Tezduyar TE (2020) Gas turbine computational flow and structure analysis with isogeometric discretization and a complex-geometry mesh generation method. Comput Mech. https://doi.org/10.1007/ s00466-020-01919-w

86. Tezduyar TE, Behr M, Mittal S, Johnson AA (1992) Computation of unsteady incompressible flows with the finite element methods: space-time formulations, iterative strategies and massively parallel implementations. In: New methods in transient analysis, PVP-Vol.246/AMD-vol.143. ASME, New York, pp 7-24

87. Tezduyar T, Aliabadi S, Behr M, Johnson A, Mittal S (1993) Parallel finite-element computation of 3D flows. Computer 26(10):2736. https://doi.org/10.1109/2.237441

88. Johnson AA, Tezduyar TE (1994) Mesh update strategies in parallel finite element computations of flow problems with moving boundaries and interfaces. Comput Methods Appl Mech Eng 119:73-94. https://doi.org/10.1016/0045-7825(94)00077-8

89. Stein K, Tezduyar T, Benney R (2003) Mesh moving techniques for fluid-structure interactions with large displacements. J Appl Mech 70:58-63. https://doi.org/10.1115/1.1530635

90. Terahara T, Takizawa K, Tezduyar TE, Tsushima A, Shiozaki K (2020) Ventricle-valve-aorta flow analysis with the space-time isogeometric discretization and topology change. Comput Mech 65:1343-1363. https://doi.org/10.1007/s00466-020-01822-4

91. Takizawa K, Tezduyar TE, Avsar R (2020) A low-distortion mesh moving method based on fiber-reinforced hyperelasticity and optimized zero-stress state. Comput Mech 65:1567-1591. https://doi. org/10.1007/s00466-020-01835-z

92. Takizawa K, Tezduyar TE, Boben J, Kostov N, Boswell C, Buscher A (2013) Fluid-structure interaction modeling of clusters of spacecraft parachutes with modified geometric porosity. Comput Mech 52:1351-1364. https://doi.org/10.1007/s00466013-0880-5

93. Tonon P, Sanches RAK, Takizawa K, Tezduyar TE (2020) A linear-elasticity-based mesh moving method with no cycle-tocycle accumulated distortion. Comput Mech. https://doi.org/10. 1007/s00466-020-01941-y

94. Tezduyar TE, Takizawa K (2019) Space-time computations in practical engineering applications: a summary of the 25-year history. Comput Mech 63:747-753. https://doi.org/10.1007/s00466018-1620-7

95. Takizawa K, Tezduyar TE (2012) Computational methods for parachute fluid-structure interactions. Arch Comput Methods Eng 19:125-169. https://doi.org/10.1007/s11831-012-9070-4

96. Takizawa K, Fritze M, Montes D, Spielman T, Tezduyar TE (2012) Fluid-structure interaction modeling of ringsail parachutes with disreefing and modified geometric porosity. Comput Mech 50:835-854. https://doi.org/10.1007/s00466-012-0761-3

97. Takizawa K, Tezduyar TE, Boswell C, Tsutsui Y, Montel K (2015) Special methods for aerodynamic-moment calculations from parachute FSI modeling. Comput Mech 55:1059-1069. https://doi.org/10.1007/s00466-014-1074-5
98. Takizawa K, Montes D, Fritze M, McIntyre S, Boben J, Tezduyar TE (2013) Methods for FSI modeling of spacecraft parachute dynamics and cover separation. Math Models Methods Appl Sci 23:307-338. https://doi.org/10.1142/S0218202513400058

99. Takizawa K, Tezduyar TE, Boswell C, Kolesar R, Montel K (2014) FSI modeling of the reefed stages and disreefing of the Orion spacecraft parachutes. Comput Mech 54:1203-1220. https://doi. org/10.1007/s00466-014-1052-y

100. Takizawa K, Tezduyar TE, Kolesar R, Boswell C, Kanai T, Montel K (2014) Multiscale methods for gore curvature calculations from FSI modeling of spacecraft parachutes. Comput Mech 54:14611476. https://doi.org/10.1007/s00466-014-1069-2

101. Takizawa K, Tezduyar TE, Kolesar R (2015) FSI modeling of the Orion spacecraft drogue parachutes. Comput Mech 55:11671179. https://doi.org/10.1007/s00466-014-1108-z

102. Takizawa K, Henicke B, Tezduyar TE, Hsu M-C, Bazilevs Y (2011) Stabilized space-time computation of wind-turbine rotor aerodynamics. Comput Mech 48:333-344. https://doi.org/10. 1007/s00466-011-0589-2

103. Takizawa K, Tezduyar TE, McIntyre S, Kostov N, Kolesar R, Habluetzel C (2014) Space-time VMS computation of windturbine rotor and tower aerodynamics. Comput Mech 53:1-15. https://doi.org/10.1007/s00466-013-0888-x

104. Takizawa K, Bazilevs Y, Tezduyar TE, Hsu M-C, Øiseth O, Mathisen KM, Kostov N, McIntyre S (2014) Engineering analysis and design with ALE-VMS and space-time methods. Arch Comput Methods Eng 21:481-508. https://doi.org/10.1007/s11831014-9113-0

105. Takizawa $K$ (2014) Computational engineering analysis with the new-generation space-time methods. Comput Mech 54:193-211. https://doi.org/10.1007/s00466-014-0999-z

106. Takizawa K, Tezduyar TE, Mochizuki H, Hattori H, Mei S, Pan L, Montel K (2015) Space-time VMS method for flow computations with slip interfaces (ST-SI). Math Models Methods Appl Sci 25:2377-2406. https://doi.org/10.1142/S0218202515400126

107. Otoguro Y, Mochizuki H, Takizawa K, Tezduyar TE (2020) Spacetime variational multiscale isogeometric analysis of a tsunamishelter vertical-axis wind turbine. Comput Mech 66:1443-1460. https://doi.org/10.1007/s00466-020-01910-5

108. Takizawa K, Henicke B, Puntel A, Kostov N, Tezduyar TE (2012) Space-time techniques for computational aerodynamics modeling of flapping wings of an actual locust. Comput Mech 50:743-760. https://doi.org/10.1007/s00466-012-0759-x

109. Takizawa K, Henicke B, Puntel A, Kostov N, Tezduyar TE (2013) Computer modeling techniques for flapping-wing aerodynamics of a locust. Comput Fluids 85:125-134. https://doi.org/10.1016/ j.compfluid.2012.11.008

110. Takizawa K, Kostov N, Puntel A, Henicke B, Tezduyar TE (2012) Space-time computational analysis of bio-inspired flapping-wing aerodynamics of a micro aerial vehicle. Comput Mech 50:761778. https://doi.org/10.1007/s00466-012-0758-y

111. Takizawa K, Tezduyar TE, Kostov N (2014) Sequentially-coupled space-time FSI analysis of bio-inspired flapping-wing aerodynamics of an MAV. Comput Mech 54:213-233. https://doi.org/ 10.1007/s00466-014-0980-x

112. Takizawa K, Tezduyar TE, Buscher A, Asada S (2014) Spacetime interface-tracking with topology change (ST-TC). Comput Mech 54:955-971. https://doi.org/10.1007/s00466-013-0935-7

113. Takizawa K, Tezduyar TE, Buscher A (2015) Space-time computational analysis of MAV flapping-wing aerodynamics with wing clapping. Comput Mech 55:1131-1141. https://doi.org/10.1007/ s00466-014-1095-0

114. Takizawa K, Bazilevs Y, Tezduyar TE, Long CC, Marsden AL, Schjodt K (2014) ST and ALE-VMS methods for patientspecific cardiovascular fluid mechanics modeling. Math Mod- 
els Methods Appl Sci 24:2437-2486. https://doi.org/10.1142/ S0218202514500250

115. Takizawa K, Schjodt K, Puntel A, Kostov N, Tezduyar TE (2012) Patient-specific computer modeling of blood flow in cerebral arteries with aneurysm and stent. Comput Mech 50:675-686. https://doi.org/10.1007/s00466-012-0760-4

116. Takizawa K, Schjodt K, Puntel A, Kostov N, Tezduyar TE (2013) Patient-specific computational analysis of the influence of a stent on the unsteady flow in cerebral aneurysms. Comput Mech 51:1061-1073. https://doi.org/10.1007/s00466-012-0790$\mathrm{y}$

117. Suito H, Takizawa K, Huynh VQH, Sze D, Ueda T (2014) FSI analysis of the blood flow and geometrical characteristics in the thoracic aorta. Comput Mech 54:1035-1045. https://doi.org/10. 1007/s00466-014-1017-1

118. Suito H, Takizawa K, Huynh VQH, Sze D, Ueda T, Tezduyar TE (2016) A geometrical-characteristics study in patient-specific FSI analysis of blood flow in the thoracic aorta. In: Bazilevs Y, Takizawa K (eds) Advances in computational fluid-structure interaction and flow simulation: new methods and challenging computations, modeling and simulation in science, engineering and technology. Springer, pp 379-386. ISBN 978-3-319-408255. https://doi.org/10.1007/978-3-319-40827-9_29

119. Takizawa K, Tezduyar TE, Uchikawa H, Terahara T, Sasaki T, Shiozaki K, Yoshida A, Komiya K, Inoue G (2018) Aorta flow analysis and heart valve flow and structure analysis. In: Tezduyar TE (ed) Frontiers in computational fluid-structure interaction and flow simulation: research from lead investigators under forty-2018, modeling and simulation in science, engineering and technology. Springer, pp 29-89. ISBN 978-3-319-96468-3. https://doi.org/10.1007/978-3-319-96469-0_2

120. Takizawa K, Tezduyar TE, Uchikawa H, Terahara T, Sasaki T, Yoshida A (2019) Mesh refinement influence and cardiaccycle flow periodicity in aorta flow analysis with isogeometric discretization. Comput Fluids 179:790-798. https://doi.org/10. 1016/j.compfluid.2018.05.025

121. Takizawa K, Tezduyar TE, Buscher A, Asada S (2014) Spacetime fluid mechanics computation of heart valve models. Comput Mech 54:973-986. https://doi.org/10.1007/s00466-014-1046-9

122. Takizawa K, Tezduyar TE (2016) New directions in spacetime computational methods. In: Bazilevs Y, Takizawa K (eds) Advances in computational fluid-structure interaction and flow simulation: new methods and challenging computations, modeling and simulation in science, engineering and technology. Springer, pp 159-178. ISBN 978-3-319-40825-5. https://doi.org/ 10.1007/978-3-319-40827-9_13

123. Takizawa K, Tezduyar TE, Terahara T, Sasaki T (2018) Heart valve flow computation with the space-time slip interface topology change (ST-SI-TC) method and isogeometric analysis (IGA). In: Wriggers P, Lenarz T (eds.) Biomedical technology: modeling, experiments and simulation, lecture notes in applied and computational mechanics. Springer, pp 77-99. ISBN 978-3-319-59547-4. https://doi.org/10.1007/978-3-319-59548-1_6

124. Takizawa K, Tezduyar TE, Terahara T, Sasaki T (2017) Heart valve flow computation with the integrated space-time VMS, slip interface, topology change and isogeometric discretization methods. Comput Fluids 158:176-188. https://doi.org/10.1016/j. compfluid.2016.11.012

125. Terahara T, Takizawa K, Tezduyar TE, Bazilevs Y, Hsu M-C (2020) Heart valve isogeometric sequentially-coupled FSI analysis with the space-time topology change method. Comput Mech 65:1167-1187. https://doi.org/10.1007/s00466-019-01813-0

126. Yu Y, Zhang YJ, Takizawa K, Tezduyar TE, Sasaki T (2020) Anatomically realistic lumen motion representation in patientspecific space-time isogeometric flow analysis of coronary arter- ies with time-dependent medical-image data. Comput Mech 65:395-404. https://doi.org/10.1007/s00466-019-01774-4

127. Takizawa K, Tezduyar TE, Kuraishi T, Tabata S, Takagi H (2016) Computational thermo-fluid analysis of a disk brake. Comput Mech 57:965-977. https://doi.org/10.1007/s00466-016-1272-4

128. Takizawa K, Tezduyar TE, Hattori H (2017) Computational analysis of flow-driven string dynamics in turbomachinery. Comput Fluids 142:109-117. https://doi.org/10.1016/j.compfluid.2016. 02.019

129. Komiya K, Kanai T, Otoguro Y, Kaneko M, Hirota K, Zhang Y, Takizawa K, Tezduyar TE, Nohmi M, Tsuneda T, Kawai M, Isono M (2019) Computational analysis of flow-driven string dynamics in a pump and residence time calculation. IOP Conf Ser Earth Environ Sci 240:062014. https://doi.org/10.1088/1755-1315/240/6/ 062014

130. Kanai T, Takizawa K, Tezduyar TE, Komiya K, Kaneko M, Hirota K, Nohmi M, Tsuneda T, Kawai M, Isono M (2019) Methods for computation of flow-driven string dynamics in a pump and residence time. Math Models Methods Appl Sci 29:839-870. https:// doi.org/10.1142/S021820251941001X

131. Otoguro Y, Takizawa K, Tezduyar TE (2017) Space-time VMS computational flow analysis with isogeometric discretization and a general-purpose NURBS mesh generation method. Comput Fluids 158:189-200. https://doi.org/10.1016/j.compfluid.2017. 04.017

132. Otoguro Y, Takizawa K, Tezduyar TE (2018) A general-purpose NURBS mesh generation method for complex geometries. In: Tezduyar TE (ed) Frontiers in computational fluid-structure interaction and flow simulation: research from lead investigators under forty-2018, modeling and simulation in science, engineering and technology. Springer, pp 399-434. ISBN 978-3-319-96468-3. https://doi.org/10.1007/978-3-319-96469-0_10

133. Otoguro Y, Takizawa K, Tezduyar TE, Nagaoka K, Mei S (2019) Turbocharger turbine and exhaust manifold flow computation with the space-time variational multiscale method and isogeometric analysis. Comput Fluids 179:764-776. https://doi.org/10.1016/j. compfluid.2018.05.019

134. Otoguro Y, Takizawa K, Tezduyar TE, Nagaoka K, Avsar R, Zhang Y (2019) Space-time VMS flow analysis of a turbocharger turbine with isogeometric discretization: computations with time-dependent and steady-inflow representations of the intake/exhaust cycle. Comput Mech 64:1403-1419. https://doi. org/10.1007/s00466-019-01722-2

135. Takizawa K, Tezduyar TE, Asada S, Kuraishi T (2016) Space-time method for flow computations with slip interfaces and topology changes (ST-SI-TC). Comput Fluids 141:124-134. https://doi. org/10.1016/j.compfluid.2016.05.006

136. Kuraishi T, Takizawa K, Tezduyar TE (2018) Space-time computational analysis of tire aerodynamics with actual geometry, road contact and tire deformation. In Tezduyar TE (ed) Frontiers in computational fluid-structure interaction and flow simulation: research from lead investigators under forty-2018, modeling and simulation in science, engineering and technology. Springer, pp 337-376. ISBN 978-3-319-96468-3. https://doi.org/10.1007/ 978-3-319-96469-0_8

137. Kuraishi T, Takizawa K, Tezduyar TE (2019) Space-time computational analysis of tire aerodynamics with actual geometry, road contact, tire deformation, road roughness and fluid film. Comput Mech 64:1699-1718. https://doi.org/10.1007/s00466019-01746-8

138. Kuraishi T, Takizawa K, Tezduyar TE (2019) Space-time isogeometric flow analysis with built-in Reynolds-equation limit. Math Models Methods Appl Sci 29:871-904. https://doi.org/10.1142/ S0218202519410021

139. Takizawa K, Tezduyar TE, Kanai T (2017) Porosity models and computational methods for compressible-flow aerodynamics of 
parachutes with geometric porosity. Math Models Methods Appl Sci 27:771-806. https://doi.org/10.1142/S0218202517500166

140. Kanai T, Takizawa K, Tezduyar TE, Tanaka T, Hartmann A (2019) Compressible-flow geometric-porosity modeling and spacecraft parachute computation with isogeometric discretization. Comput Mech 63:301-321. https://doi.org/10.1007/s00466-018-1595-4

141. Bazilevs Y, Hughes TJR (2008) NURBS-based isogeometric analysis for the computation of flows about rotating components. Comput Mech 43:143-150

142. Hsu M-C, Bazilevs Y (2012) Fluid-structure interaction modeling of wind turbines: simulating the full machine. Comput Mech 50:821-833

143. Hughes TJR, Cottrell JA, Bazilevs Y (2005) Isogeometric analysis: CAD, finite elements, NURBS, exact geometry, and mesh refinement. Comput Methods Appl Mech Eng 194:4135-4195

144. Takizawa K, Tezduyar TE (2014) Space-time computation techniques with continuous representation in time (ST-C). Comput Mech 53:91-99. https://doi.org/10.1007/s00466-013-0895-y

145. Tezduyar TE, Cragin T, Sathe S, Nanna B (2007) FSI computations in arterial fluid mechanics with estimated zero-pressure arterial geometry. In: Onate E, Garcia J, Bergan P, Kvamsdal T (eds) Marine 2007. CIMNE, Barcelona

146. Tezduyar TE, Sathe S, Schwaab M, Conklin BS (2008) Arterial fluid mechanics modeling with the stabilized space-time fluidstructure interaction technique. Int J Numer Meth Fluids 57:601629. https://doi.org/10.1002/fld.1633

147. Takizawa K, Christopher J, Tezduyar TE, Sathe S (2010) Spacetime finite element computation of arterial fluid-structure interactions with patient-specific data. Int J Numer Methods Biomed Eng 26:101-116. https://doi.org/10.1002/cnm.1241

148. Takizawa K, Moorman C, Wright S, Purdue J, McPhail T, Chen PR, Warren J, Tezduyar TE (2011) Patient-specific arterial fluidstructure interaction modeling of cerebral aneurysms. Int J Numer Meth Fluids 65:308-323. https://doi.org/10.1002/fld.2360

149. Tezduyar TE, Takizawa K, Brummer T, Chen PR (2011) Spacetime fluid-structure interaction modeling of patient-specific cerebral aneurysms. Int J Numer Methods Biomed Eng 27:1665-1710. https://doi.org/10.1002/cnm.1433

150. Takizawa K, Takagi H, Tezduyar TE, Torii R (2014) Estimation of element-based zero-stress state for arterial FSI computations. Comput Mech 54:895-910. https://doi.org/10.1007/s00466-0130919-7

151. Takizawa K, Torii R, Takagi H, Tezduyar TE, Xu XY (2014) Coronary arterial dynamics computation with medical-image-based time-dependent anatomical models and element-based zero-stress state estimates. Comput Mech 54:1047-1053. https://doi.org/10. 1007/s00466-014-1049-6

152. Takizawa K, Tezduyar TE, Sasaki T (2018) Estimation of elementbased zero-stress state in arterial FSI computations with isogeometric wall discretization. In: Wriggers P, Lenarz T (eds) Biomedical technology: modeling, experiments and simulation, lecture notes in applied and computational mechanics. Springer, pp 101-122. ISBN 978-3-319-59547-4. https://doi.org/10.1007/ 978-3-319-59548-1_7

153. Takizawa K, Tezduyar TE, Sasaki T (2017) Aorta modeling with the element-based zero-stress state and isogeometric discretization. Comput Mech 59:265-280. https://doi.org/10.1007/s00466016-1344-5

154. Sasaki T, Takizawa K, Tezduyar TE (2019) Aorta zero-stress state modeling with T-spline discretization. Comput Mech 63:13151331. https://doi.org/10.1007/s00466-018-1651-0

155. Sasaki T, Takizawa K, Tezduyar TE (2019) Medical-image-based aorta modeling with zero-stress-state estimation. Comput Mech 64:249-271. https://doi.org/10.1007/s00466-019-01669-4

156. Takizawa K, Tezduyar TE, Sasaki T (2019) Isogeometric hyperelastic shell analysis with out-of-plane deformation mapping.
Comput Mech 63:681-700. https://doi.org/10.1007/s00466-0181616-3

157. Bazilevs Y, Hsu M-C, Kiendl J, Benson DJ (2012) A computational procedure for pre-bending of wind turbine blades. Int $\mathrm{J}$ Numer Meth Eng 89:323-336

158. Bazilevs Y, Deng X, Korobenko A, di Scalea FL, Todd MD, Taylor SG (2015) Isogeometric fatigue damage prediction in large-scale composite structures driven by dynamic sensor data. J Appl Mech 82:091008

159. Herrema AJ, Johnson EL, Proserpio D, Wu MCH, Kiendl J, Hsu M-C (2019) Penalty coupling of non-matching isogeometric Kirchhoff-Love shell patches with application to composite wind turbine blades. Comput Methods Appl Mech Eng 346:810-840

160. Herrema AJ, Kiendl J, Hsu M-C (2019) A framework for isogeometric-analysis-based optimization of wind turbine blade structures. Wind Energy 22:153-170

161. Johnson EL, Hsu M-C (2020) Isogeometric analysis of ice accretion on wind turbine blades. Comput Mech 66:311-322

162. Hughes TJR, Mallet M, Mizukami A (1986) A new finite element formulation for computational fluid dynamics: II. Beyond SUPG. Comput Methods Appl Mech Eng 54:341-355

163. Tezduyar TE, Park YJ (1986) Discontinuity capturing finite element formulations for nonlinear convection-diffusion-reaction equations. Comput Methods Appl Mech Eng 59:307-325. https:// doi.org/10.1016/0045-7825(86)90003-4

164. Akin JE, Tezduyar T, Ungor M, Mittal S (2003) Stabilization parameters and Smagorinsky turbulence model. J Appl Mech 70:2-9. https://doi.org/10.1115/1.1526569

165. Akin JE, Tezduyar TE (2004) Calculation of the advective limit of the SUPG stabilization parameter for linear and higher-order elements. Comput Methods Appl Mech Eng 193:1909-1922. https:// doi.org/10.1016/j.cma.2003.12.050

166. Tezduyar TE, Osawa Y (2000) Finite element stabilization parameters computed from element matrices and vectors. Comput Methods Appl Mech Eng 190:411-430. https://doi.org/10.1016/ S0045-7825(00)00211-5

167. Hsu M-C, Bazilevs Y, Calo VM, Tezduyar TE, Hughes TJR (2010) Improving stability of stabilized and multiscale formulations in flow simulations at small time steps. Comput Methods Appl Mech Eng 199:828-840. https://doi.org/10.1016/j.cma.2009.06.019

168. Tezduyar TE (2001) Adaptive determination of the finite element stabilization parameters. In: Proceedings of the ECCOMAS computational fluid dynamics conference 2001. CD-ROM, Swansea, Wales, United Kingdom

169. Tezduyar TE (2003) Computation of moving boundaries and interfaces and stabilization parameters. Int J Numer Meth Fluids 43:555-575. https://doi.org/10.1002/fld.505

170. Tezduyar TE (2004) Finite element methods for fluid dynamics with moving boundaries and interfaces. In Stein E, Borst RD, Hughes TJR (eds) Encyclopedia of computational mechanics, volume 3: fluids, chapter 17. Wiley. ISBN 978-0-470-84699-5. https://doi.org/10.1002/0470091355.ecm069

171. Tezduyar TE, Sathe S (2007) Modeling of fluid-structure interactions with the space-time finite elements: solution techniques. Int J Numer Meth Fluids 54:855-900. https://doi.org/10.1002/fld. 1430

172. Corsini A, Menichini C, Rispoli F, Santoriello A, Tezduyar TE (2009) A multiscale finite element formulation with discontinuity capturing for turbulence models with dominant reactionlike terms. J Appl Mech 76:021211. https://doi.org/10.1115/1.3062967

173. Rispoli F, Saavedra R, Menichini F, Tezduyar TE (2009) Computation of inviscid supersonic flows around cylinders and spheres with the V-SGS stabilization and YZ $\beta$ shock-capturing. J Appl Mech 76:021209. https://doi.org/10.1115/1.3057496

174. Corsini A, Iossa C, Rispoli F, Tezduyar TE (2010) A DRD finite element formulation for computing turbulent reacting flows in gas 
turbine combustors. Comput Mech 46:159-167. https://doi.org/ 10.1007/s00466-009-0441-0

175. Corsini A, Rispoli F, Tezduyar TE (2011) Stabilized finite element computation of NOx emission in aero-engine combustors. Int J Numer Meth Fluids 65:254-270. https://doi.org/10.1002/fld. 2451

176. Corsini A, Rispoli F, Tezduyar TE (2012) Computer modeling of wave-energy air turbines with the SUPG/PSPG formulation and discontinuity-capturing technique. J Appl Mech 79:010910. https://doi.org/10.1115/1.4005060

177. Corsini A, Rispoli F, Sheard AG, Tezduyar TE (2012) Computational analysis of noise reduction devices in axial fans with stabilized finite element formulations. Comput Mech 50:695-705. https://doi.org/10.1007/s00466-012-0789-4

178. Kler PA, Dalcin LD, Paz RR, Tezduyar TE (2013) SUPG and discontinuity-capturing methods for coupled fluid mechanics and electrochemical transport problems. Comput Mech 51:171-185. https://doi.org/10.1007/s00466-012-0712-z

179. Corsini A, Rispoli F, Sheard AG, Takizawa K, Tezduyar TE, Venturini P (2014) A variational multiscale method for particle-cloud tracking in turbomachinery flows. Comput Mech 54:1191-1202. https://doi.org/10.1007/s00466-014-1050-0

180. Rispoli F, Delibra G, Venturini P, Corsini A, Saavedra R, Tezduyar TE (2015) Particle tracking and particle-shock interaction in compressible-flow computations with the V-SGS stabilization and $\mathrm{YZ} \beta$ shock-capturing. Comput Mech 55:1201-1209. https:// doi.org/10.1007/s00466-015-1160-3

181. Cardillo L, Corsini A, Delibra G, Rispoli F, Tezduyar TE (2016) Flow analysis of a wave-energy air turbine with the SUPG/PSPG stabilization and Discontinuity-Capturing Directional Dissipation. Comput Fluids 141:184-190. https://doi.org/ 10.1016/j.compfluid.2016.07.011

182. Castorrini A, Corsini A, Rispoli F, Venturini P, Takizawa K, Tezduyar TE (2016) Computational analysis of wind-turbine blade rain erosion. Comput Fluids 141:175-183. https://doi.org/10. 1016/j.compfluid.2016.08.013

183. Castorrini A, Corsini A, Rispoli F, Venturini P, Takizawa K, Tezduyar TE (2019) Computational analysis of performance deterioration of a wind turbine blade strip subjected to environmental erosion. Comput Mech 64:1133-1153. https://doi.org/10.1007/ s00466-019-01697-0
184. Castorrini A, Venturini P, Corsini A, Rispoli F, Takizawa K, Tezduyar TE (2020) Computational analysis of particle-laden-airflow erosion and experimental verification. Comput Mech 65:15491565. https://doi.org/10.1007/s00466-020-01834-0

185. Takizawa K, Tezduyar TE, Otoguro Y (2018) Stabilization and discontinuity-capturing parameters for space-time flow computations with finite element and isogeometric discretizations. Comput Mech 62:1169-1186. https://doi.org/10.1007/s00466-018-1557$\mathrm{x}$

186. Takizawa K, Ueda Y, Tezduyar TE (2019) A node-numberinginvariant directional length scale for simplex elements. Math Models Methods Appl Sci 29:2719-2753. https://doi.org/10. 1142/S0218202519500581

187. Ueda Y, Otoguro Y, Takizawa K, Tezduyar TE (2020) Elementsplitting-invariant local-length-scale calculation in B-spline meshes for complex geometries. Math Models Methods Appl Sci 30:2139-2174. https://doi.org/10.1142/S0218202520500402

188. Cheah SC, Lacovides H, Jackson DC, Ji H, Launder BE (1994) LDA investigation of the flow development through rotating Uducts. In: Proceedings of the ASME turbo expo 5

189. Sabersky RH, Acosta AJ (1964) Fluid flow, a first course in fluid mechanics. Collier-Macmillian

190. Pirozzoli S, Modesti D, Orlandi P, Grasso F (2018) Turbulence and secondary motions in square duct flow. J Fluid Mech 840:631655. https://doi.org/10.1017/jfm.2018.66

191. Bazilevs Y, Hughes TJR (2007) Weak imposition of Dirichlet boundary conditions in fluid mechanics. Comput Fluids 36:1226

192. Hsu M-C, Akkerman I, Bazilevs Y (2012) Wind turbine aerodynamics using ALE-VMS: validation and role of weakly enforced boundary conditions. Comput Mech 50:499-511

Publisher's Note Springer Nature remains neutral with regard to jurisdictional claims in published maps and institutional affiliations. 